\title{
The development of dynamic models for a dense medium separation circuit in coal beneficiation
}

\author{
E.J. Meyer ${ }^{\mathrm{a}, \mathrm{b}}$, I.K. Craig ${ }^{\mathrm{b}, *}$ \\ ${ }^{a}$ MES - Core Process Solutions, Exxaro Resources, PO Box 9229, Pretoria 0001, South Africa \\ ${ }^{\mathrm{b}}$ Department of Electrical, Electronic and Computer Engineering, University of Pretoria, Pretoria 0002, South Africa
}

\section{A R T I C L E I N F O}

\section{Article history:}

Received 26 March 2010

Accepted 30 May 2010

Available online $\mathrm{xxxx}$

\section{Keywords:}

Dense medium separation

Coal beneficiation

Dynamic modelling

Process control

Simulation

Parameter identifiability

\begin{abstract}
A B S T R A C T
Often the most difficult step in establishing a control system is the development of a suitable dynamic process model. As such a model is not available elsewhere, a first principle dynamic mathematical model was developed for a coal dense medium separation circuit. Each unit operation was modelled individually and then integrated together to form a complete non-linear state-space model for the circuit. This model was used to simulate the process and it was validated using real process data derived from a plant experiment.

When developing models from first principles, it is necessary to estimate the model parameters. These parameters, specifically for non-linear state-space relationships, require a unique solution. A parameter identifiability method was used to show that the non-linear dynamic models developed have unique parameters for a specific set of input-output data.
\end{abstract}

(c) 2010 Elsevier Ltd. All rights reserved.

\section{Introduction}

Raw coal that is mined contains a number of impurities and is typically processed to improve its overall quality. The mineral processing of this run-of-mine (ROM) coal involves a complicated and sophisticated operation including comminution, classification and separation. These separation processes normally make use of particle classification on the basis of density (England et al., 2002). Coal, typically being lighter, is separated from the heavier gangue by utilising the difference in specific gravity. These processes can make use of mediums that are made to have specific relative densities to ensure the separation of coal from gangue.

Coal beneficiation primarily makes use of gravity separation in coal washing (Majumder et al., 2004). It is explained that dense medium separation (DMS), specifically the dense medium cyclone (DMC), is the main processing unit used for cleaning coal, beneficiating nearly $55 \%$ of coal that is washed worldwide (Honaker and Patwardhan, 2006; de Korte, 2003a). The United States makes use of the DMS process for $65 \%$ of its washed coal. It can be determined from the data collected by de Korte (2003b) that $98 \%$ of the 53 coal-preparation plants in South Africa are making use of the DMC as their beneficiating unit.

Implementing a control system requires a high level of process understanding (Lipták, 1995) that can lead to improved plant performance in terms of stability and economics (Bauer and Craig,

\footnotetext{
* Corresponding author. Tel.: +27 12420 2172; fax: +27 123625000

E-mail address: icraig@postino.up.ac.za (I.K. Craig).
}

2008). Process control enables the reduction of plant upsets due to disturbances and ensures a plant keeps to its desired setpoints, i.e. it reduces the difference between the desired specifications and measured control variables. Control systems typically make use of a mathematical model that incorporates the plant dynamics, and a well controlled plant will reach its steady state in the fastest time possible after start-up or process setpoint changes.

By applying the concepts of process control to DMS of coal, there is an opportunity to improve product yield and quality, e.g. reducing ash in the coal products. Process control could allow for an improvement in current coal beneficiation operations and it is for this reason that the dynamic DMS circuit model described here was developed.

Mathematical models are generally used in process controller design to improve process performance and stability and ultimately ensure economic benefits (Bauer and Craig, 2008). It is often necessary to develop a model that is simple enough to be used for control, but sophisticated enough to capture the plant dynamics. Craig and Henning (2000) describe a general control framework, illustrated in Fig. 1, where a mathematical model of the real plant needs to be developed before a control system can be designed. Once the control system performs satisfactorily in simulation it is then implemented and monitored to ensure its value has been realised.

Many static models have been developed for dense medium separation circuits. However, these models are typically not suitable for dynamic controller design for which models that describe the time evolution of variables are required. Napier-Munn (1991) 


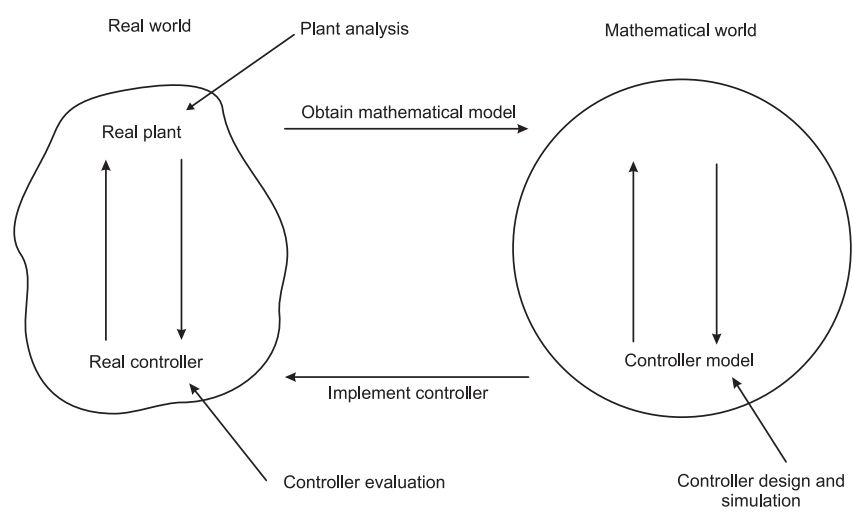

Fig. 1. General control framework (Craig and Henning, 2000).

developed a static model for a DMC, which incorporates the partition factor as a function of relative density (RD) and ore feed particle size. This model was derived by substituting equations from Lynch (1977), King and Juckes (1984), King and Juckes (1988).

Scott and Napier-Munn (1992) developed a similar type of model in which the separation efficiency has been used. Another technique that has been used to model the size-density partition surface of a DMC without the use of the pivot phenomena is stochastic modelling (Rao et al., 2003). A model, which incorporates both size and density partitions, was developed by Rao (2004) who used a Weibull function. This efficiency model makes use of pivot coordinates and density that is size-dependent, as developed by Plitt (1971). A more complicated model developed by Clarkson (1983) makes use of a force balance with turbulence to include more operating variables to simulate the performance of separation. Erasmus (1973) developed an equation which can be fitted to the partition curve by making use of an ideal washer in which no misplacement occurs. This can be evaluated cyclically over time (Napier-Munn, 1991) to obtain an imperfect performance regression model (Erasmus, 1973) that must be fitted to sink and float data.

A computer simulation by Firth et al. (1983) was developed to simulate the efficiency of DMS processes. This technique requires a large number of partition coefficient data sets and feed composition data divided into several relative density fractions with respect to each size fraction. Sufficient information on the separation process and ore feed size distribution with washability data is required in order for the simulation to be accurate.

A number of hydrocyclone models have been developed and are described by Chen et al. (2000). These models, however, are primarily developed for particle size classification and not particle separation due to density.

Other DMC models have been developed that make use of more sophisticated techniques such as computational simulations using Eulerian models for the medium and Lagrangian models for the coal particles (Suasnabar and Fletcher, 1999). Brennan (2003) reports on an algebraic slip mixture model which makes use of computational fluid dynamics (CFD) to solve the Reynolds averaged Navier Stokes equations. Cortés and Gil (2007) indicate that CFD modelling can become very costly owing to the unsteady nature of the flow that requires large eddy simulations or direct numerical simulations.

CFD models that incorporate Navier Stokes equations (Cortés and Gil, 2007) have also been developed for the DMC; however, these models are computationally very costly and are difficult to incorporate into an online controller.

A model developed for dense medium baths or drums is referred to by Napier-Munn (1991). This model, developed by Scott and Lyman (1987), uses sedimentation theory to express the sepa- ration cutpoint within the drum. Napier-Munn (1991) determined a partition factor equation for the drum separator.

Similar regression type models have also been developed for screens. It is indicated (Firth et al., 1983) that Gottfried (1973) developed a generalised equation for wet screening, which can be used to evaluate the partition coefficients per particle size fraction.

Section 2 of this paper describes the DMS process modelled in this paper. A motivation for performing the study is also discussed by using an actual DMS plant to illustrate possible process improvements. Section 3 explains how the different equipment models have been developed from first principles. The model parameter estimation method, identifiability and validation are described in Section 4. A short explanation of the industrial experiment that was conducted is also given in this section. Section 5 illustrates the different model simulation results that were obtained and Section 6 concludes the paper.

\section{The DMS process and motivation for control}

A DMS circuit example and motivation for process improvement is described below.

\subsection{The DMS process}

Fig. 2 illustrates a typical configuration of a DMS plant with two modules. The ROM coal ore is crushed and screened to a manageable size before it is processed by the DMS plant. This ore is typically classified by a double-deck wet screen where the oversize of the first deck is $+25 \mathrm{~mm}$ material, which is usually beneficiated using a dense medium drum separator. The oversize of the bottom deck reports as $+6 \mathrm{~mm}$ and $-25 \mathrm{~mm}$ material, which is beneficiated using a coarse DMC. The undersize is collected and classified further using a single-deck dewatering screen to remove slime $(-1 \mathrm{~mm})$. The oversize is beneficiated using a fine DMC while the undersize is processed with an ultrafine DMC.

Most DMC circuits look similar to that represented in Fig. 2, where the sized ore is mixed with a magnetite medium and pumped into the inlet of the DMC. The product and discard are washed to recover the medium, which is collected and used in a closed circuit. A density controller manipulates the medium RD by regulating the amount of water that is added to it. The tag names used to describe the measuring instruments in Fig. 2 are indicated in Table 1. For the purposes of this study, only the fine cyclone circuit is used for model validation and simulation. However, it is possible to expand the models to the other cyclone circuits.

\subsection{Motivation for DMS process control}

By analysing product yield and product quality data from an actual DMS plant, process improvement by making use of process control can be evaluated. If variations or oscillations in product yield and quality due to disturbances or changes in setpoints are found, control could eliminate or reduce such deviations.

The yield from an actual DMS plant is shown in Fig. 3 using a sample time of $60 \mathrm{~s}$ for the entire month of October 2008. The yield varies greatly during the month, possibly owing to instability or lack of control and changes in setpoints. It must be noted, however, that changes in setpoints will occur to enable the production team to produce various products of different ash contents based on the washability curve of the ore.

Using the yield curve in Fig. 3, a Fast Fourier Transform (FFT) (Fig. 4) can be generated. The larger spikes in the graph indicate prevalent oscillations having associated periods in the yield 


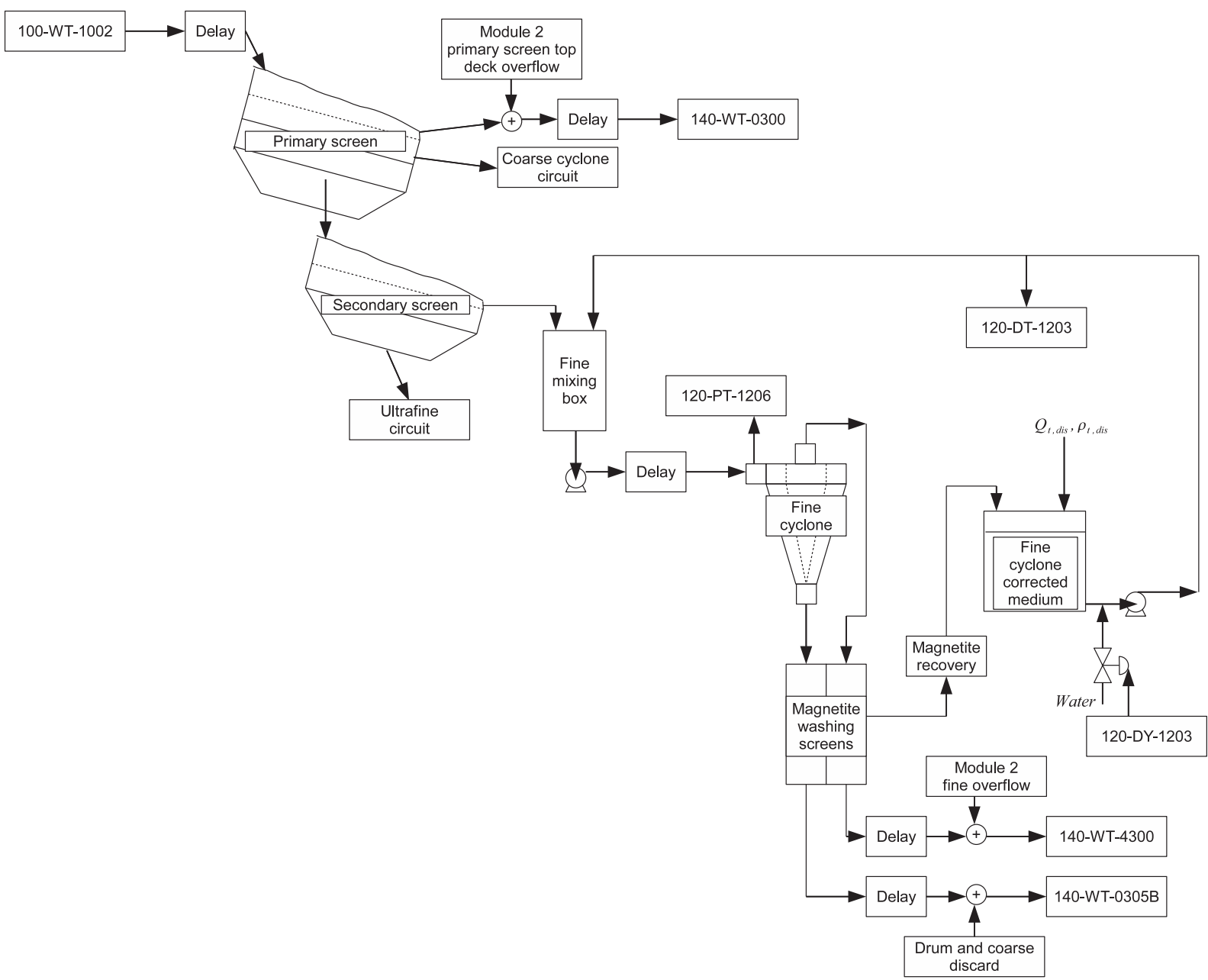

Fig. 2. Typical DMS plant process flow and instrumentation diagram.

Table 1

DMS plant instrumentation tag names.

\begin{tabular}{ll}
\hline Tag name & Description \\
\hline L120-LT-1210 & $\begin{array}{l}\text { Module one circulating medium cyclone sump } \\
\text { ultrasonic level transmitter }\end{array}$ \\
L120-PT-1206 & Module one fine cyclone pressure \\
L100-WT-1002 & $\begin{array}{l}\text { Plant feed conveyor one belt scale } \\
\text { L140-WT-0300 }\end{array}$ \\
Drum feed conveyor belt scale \\
L140-WT-0305B & Combined discard conveyor belt scale \\
L140-WT-4300 & $\begin{array}{l}\text { Stacker conveyor belt scale } \\
\text { L120-DY-1203 }\end{array}$ \\
& $\begin{array}{l}\text { Circulating medium fine cyclone module one current-to- } \\
\text { Module one circulating medium density }\end{array}$ \\
\hline
\end{tabular}

time-based curve. The average yield for October was 51.3\%, with a standard deviation of $25.1 \%$.

In order to examine some of these variations more closely, an hour of data sampled every $1 \mathrm{~s}$ is used. Fig. 5 illustrates this curve for a typical plant start-up and operating mode. The FFT of this curve has also been computed (Fig. 6) to illustrate the oscillations for that hour in more detail. It can be seen that there are spikes, for example, at frequencies $1.1 \mathrm{mHz}, 2.2 \mathrm{mHz}, 3.1 \mathrm{mHz}, 4.6 \mathrm{mHz}$ and $11.8 \mathrm{mHz}$. This corresponds to oscillations in Fig. 5 having time periods of $15 \mathrm{~min}, 7.5 \mathrm{~min}, 5.4 \mathrm{~min}, 3.6 \mathrm{~min}$ and $1.4 \mathrm{~min}$.

Figs. 7 and 9 illustrate the ash percentages of the peas and duff products for the month of October 2008 at a sampling period of $2 \mathrm{~h}$. It can be seen that product quality (i.e. ash content) varies signifi-

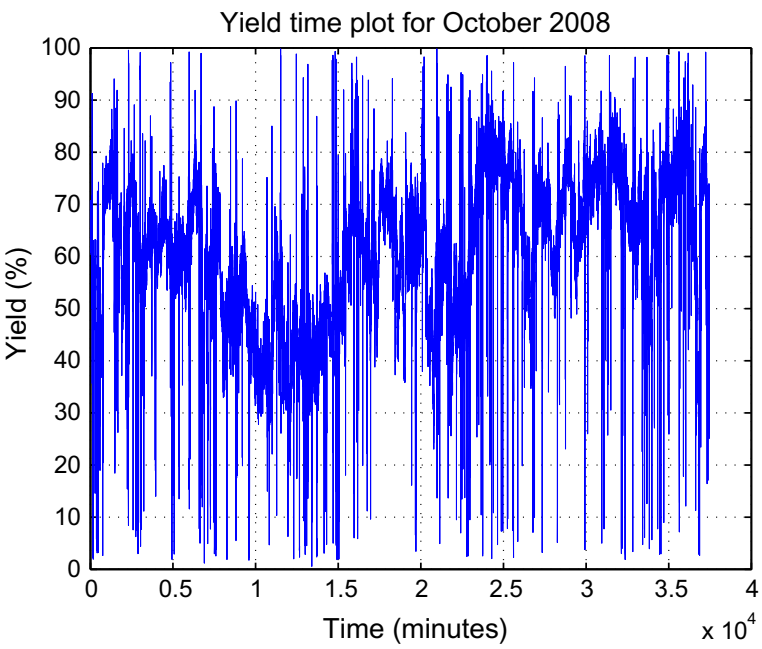

Fig. 3. Yield over the month of October 2008.

cant in the figures. The average ash content for the peas product during October 2008 is $15.4 \%$ with a standard deviation of $2 \%$. The average ash content for the duff product during October 2008 is $15.9 \%$, with a standard deviation of $2.1 \%$. The correlation between the peas and duff ash content data is $68 \%$, which indicates the distribution of ash from the ore is similar for the two products. 


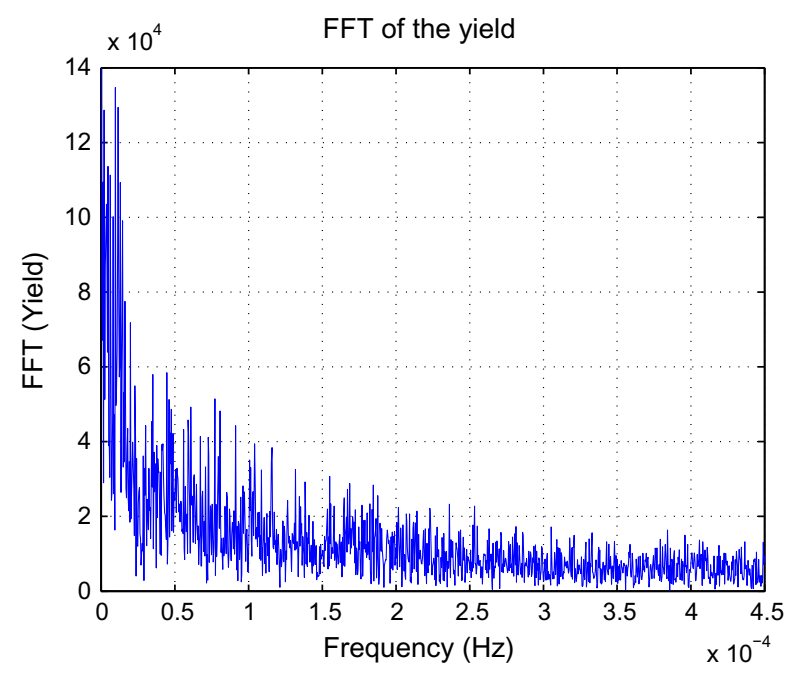

Fig. 4. FFT of the yield for October 2008 .

Yield time plot for a typical hour during October 2008

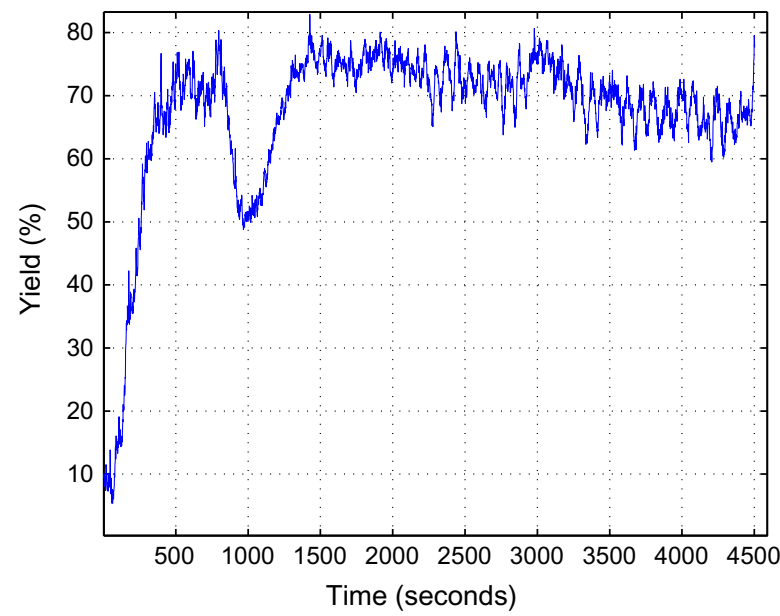

Fig. 5. Yield for an hour during October 2008.

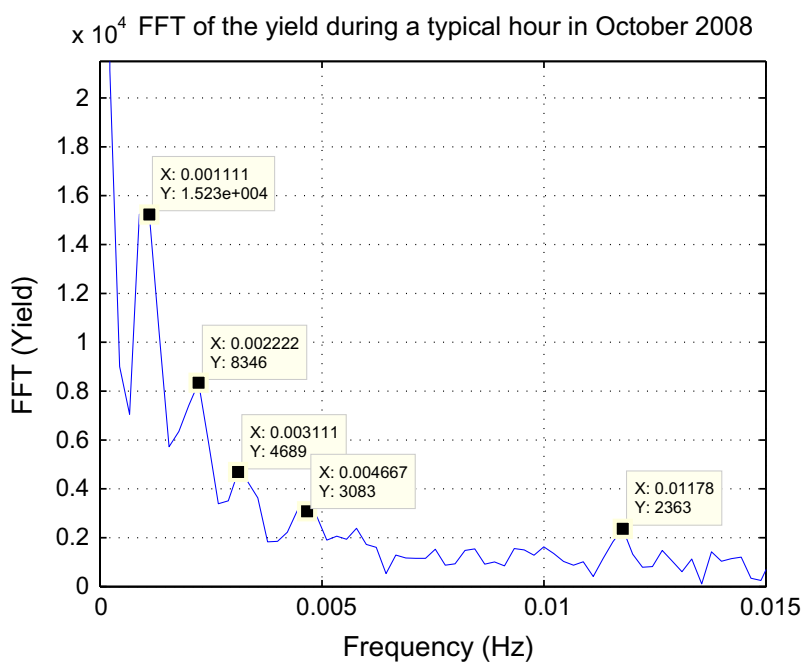

Fig. 6. FFT of the yield for an hour during October 2008 .

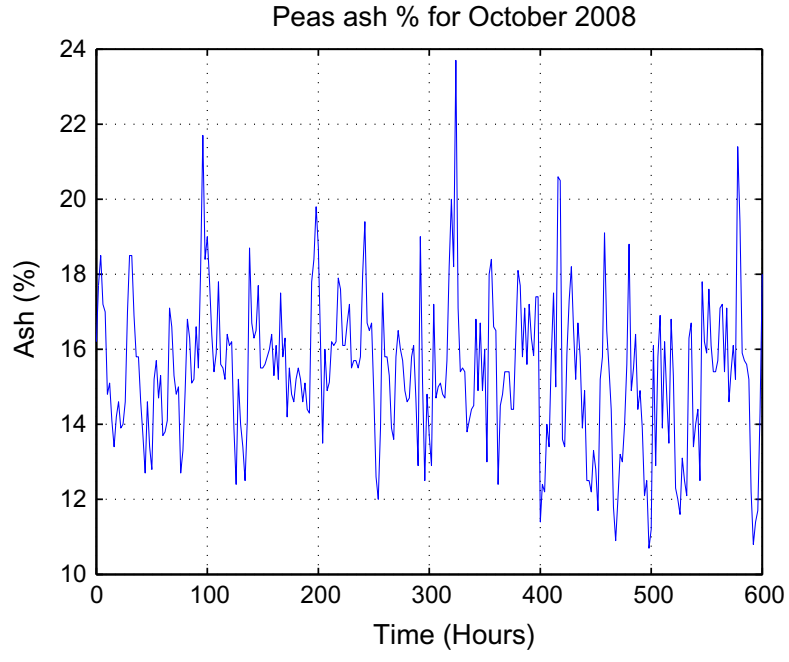

Fig. 7. Ash percentage of the peas product during October 2008.

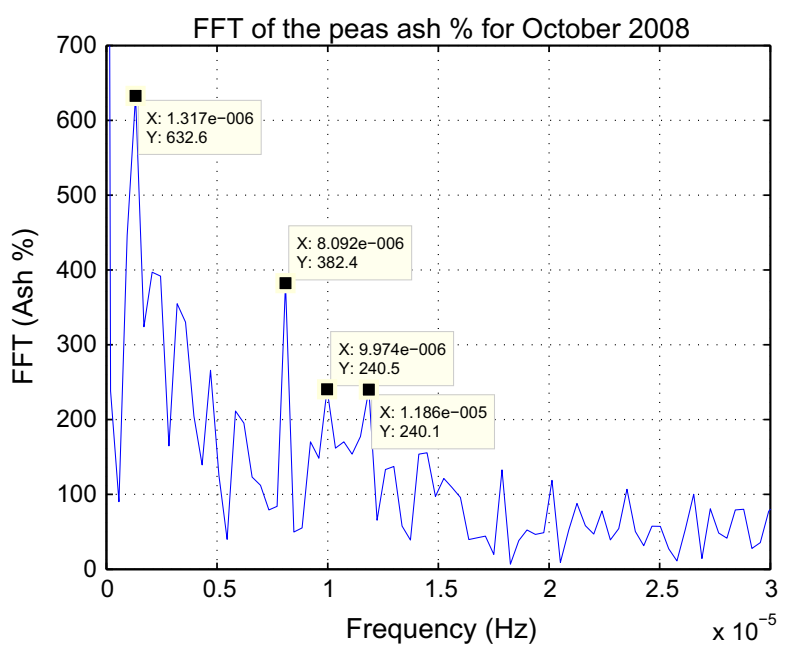

Fig. 8. FFT of the peas ash percentage for October 2008.

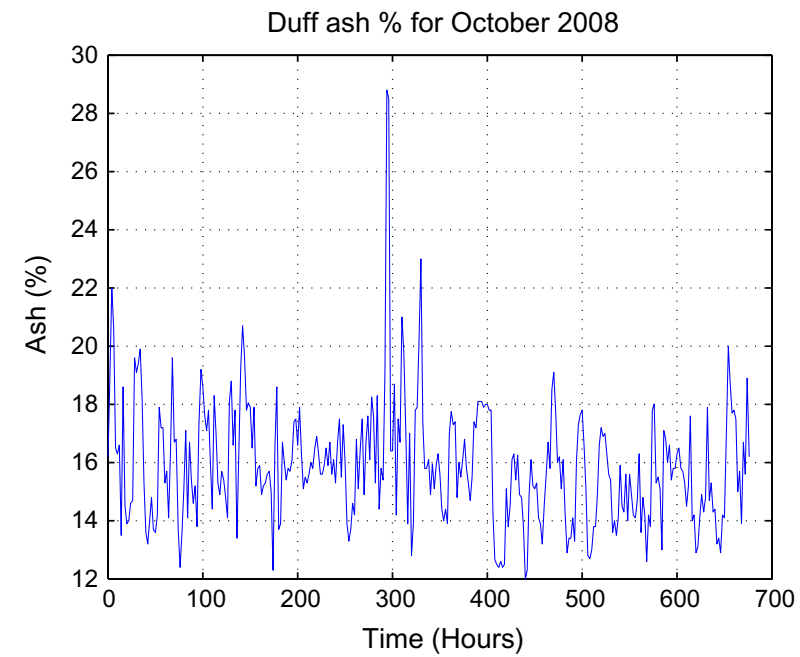

Fig. 9. Ash percentage of the duff product during October 2008. 


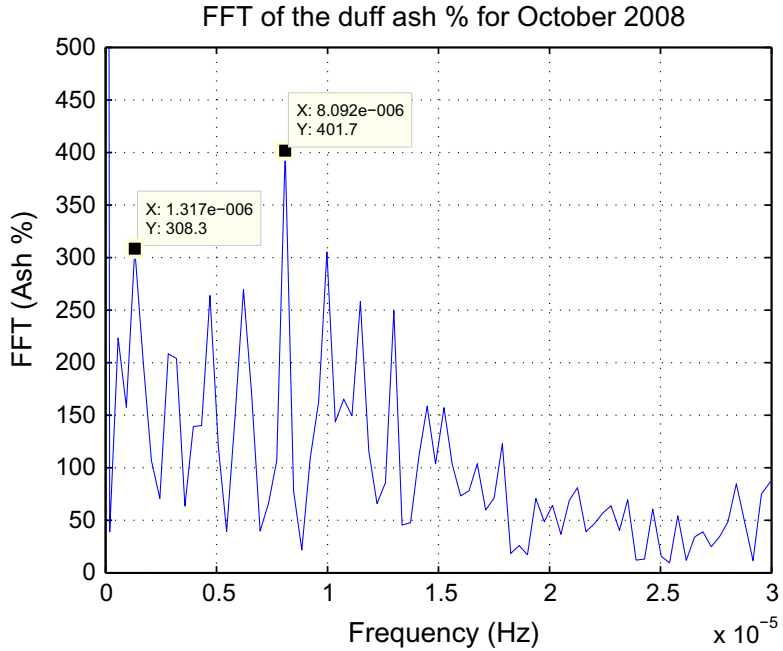

Fig. 10. FFT of the duff ash percentage for October 2008.

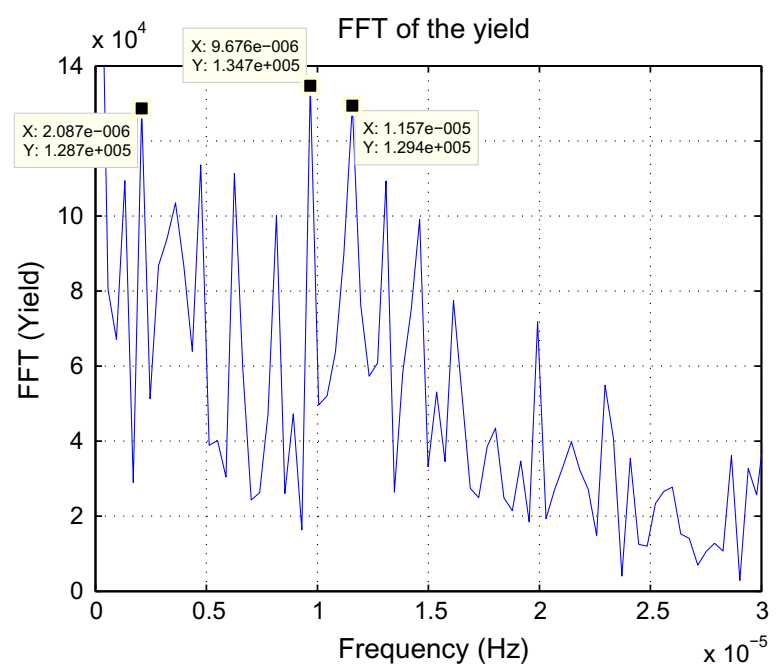

Fig. 11. FFT of the yield for October 2008.

The FFT for the peas and duff ash content curves is computed and illustrated in Figs. 8 and 10. There are spikes in the peas ash percentage FFT at frequencies $1.3 \mu \mathrm{Hz}, 8.1 \mu \mathrm{Hz}, 10.0 \mu \mathrm{Hz}$ and $11.9 \mu \mathrm{Hz}$. This corresponds to oscillations in Fig. 7 having time periods of 8.9 days, 1.4 days, 1.2 days and $23 \mathrm{~h}$. The spikes for the duff ash percentage FFT are at frequencies $1.3 \mu \mathrm{Hz}$ and $8.1 \mu \mathrm{Hz}$, which show a similar response in oscillations to the peas ash percentage FFT with 8.9 days and 1.4 days.

By reducing the frequency scale of Fig. 4 to be of a similar range to Figs. 8 and 10, the yield frequency response can be compared to the frequency response for ash percentages of peas and duff (Fig. 11). Spikes occur at frequencies $2.277 \mu \mathrm{Hz}, 9.866 \mu \mathrm{Hz}$ and $11.76 \mu \mathrm{Hz}$, which correspond to oscillations having time periods of 5.1 days, 1.2 days and $23.6 \mathrm{~h}$.

The relationship between yield and ash content at specific separation densities can be seen from the comparison of the frequency responses of the yield (Fig. 11) and ash contents in peas (Fig. 8) and duff (Fig. 10).

Disturbances or oscillations in the yield and product qualities indicate that there is an opportunity for process improvement in this DMS plant. Process control can be used to provide this improvement by ensuring the plant runs closer to steady state and ensure that setpoint changes are tracked properly. An improvement to the process, such as improvement in average yield or ash content, can have significant financial implications.

\section{Model development}

The DMS circuit models described below were all developed from first principles.

\subsection{Single-deck screen}

In developing a dynamic model for the single-deck screen, the conservation of overall mass was used. This was applied to each section of the screen to form an approximation of a distributed parameter system. Fig. 12 illustrates a simplification of this mass distribution. The following is a list of assumptions were made for the modelling of the single-deck screen:

- The screen is a distributed parameter system, but can be approximated with $n$ first order lumped parameter systems or components.

- The overflow and underflow mass feed rates $\left(W_{f, i}\right.$ and $\left.W_{u f, i}\right)$ of each component $i$ are proportional to their mass $\left(M_{f, i}\right)$ on top of each component $i$.

- The proportion of mass split $\left(\alpha_{f}\right)$ for each component $i$ is dependent on the particle size distribution of the feed $\left(\sqrt[n]{\frac{W_{f, n}}{W_{f, 0}}}\right)$.

Using these assumptions, the rate of change of mass of component $i$ is given as,

$\frac{d M_{f, i}}{d t}=W_{f, i-1}-\alpha_{f} \frac{M_{f, i}}{\tau_{f}}-\left(1-\alpha_{f}\right) \frac{M_{f, i}}{\tau_{f, u f}}$.

Modelling each mass component $i$ of the single-deck screen for a maximum of $n$ components, result in $W_{f, 0}$ being the initial feed into the screen and $W_{f, n}$ being the final mass feed rate of the

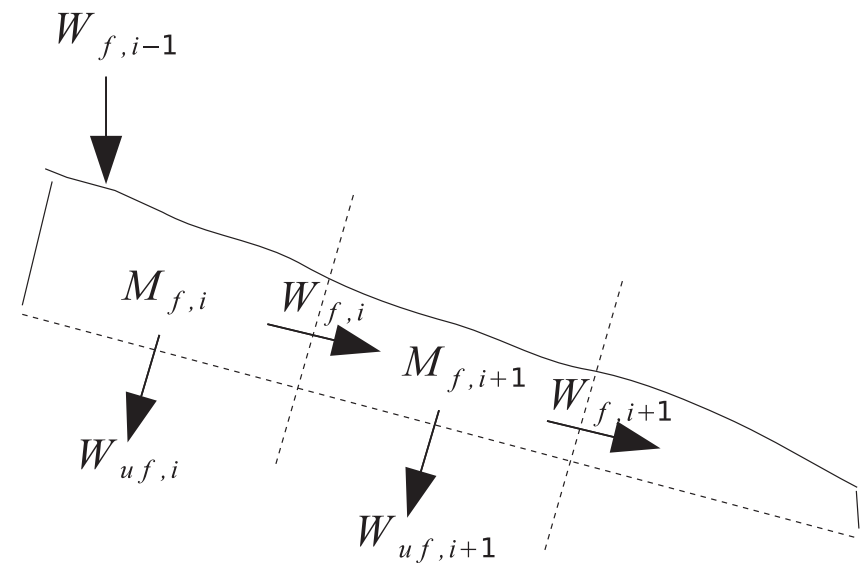

Fig. 12. Simplified representation of the mass distribution for a single-deck screen.

Table 2

Single-deck screen model variables and descriptions.

\begin{tabular}{ll}
\hline Variable & Description \\
\hline$W_{f, i-1}$ & Mass feed rate of the ore fed into component $i(\mathrm{~kg} / \mathrm{s})$ \\
$W_{f, i}$ & Mass feed rate of the ore overflow exiting mass component $i(\mathrm{~kg} / \mathrm{s})$ \\
$W_{u f, i}$ & Mass feed rate of the ore underflow exiting mass component $i(\mathrm{~kg} / \mathrm{s})$ \\
$M_{f, i}$ & Mass of ore for mass component $i(\mathrm{~kg})$ \\
$\alpha_{f}$ & Percentage of mass split for mass component $i$ \\
$\tau_{f}$ & Time taken for ore to be transported over screen component $i(\mathrm{~s})$ \\
$\tau_{f, u f}$ & Time taken for ore to be transported through screen component $i(\mathrm{~s})$ \\
\hline
\end{tabular}




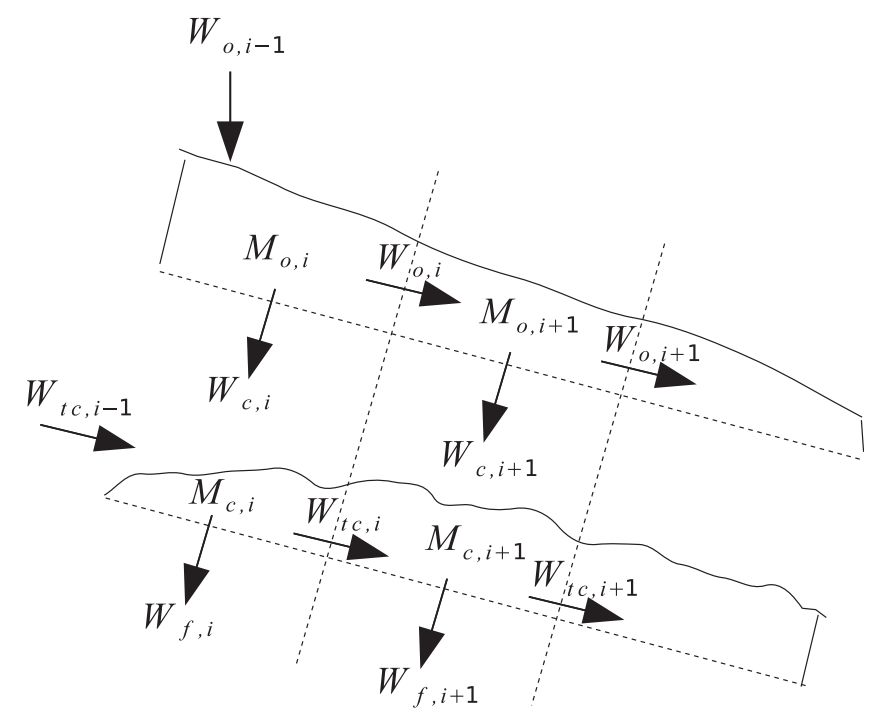

Fig. 13. Simplified representation of the mass distribution for a double-deck screen.

oversize material. The undersize material is collected and can be taken as the sum of all underflow mass components (i.e. $\left.\sum_{i=1}^{n} W_{u f, i}\right)$. The associated variables for this model are described in Table 2.

\subsection{Double-deck screen}

Similar to the development of the single-deck screen dynamic model, the conservation of overall mass is also used here, and is applied to each section of each deck of the double-deck screen to form an approximation of a distributed parameter system. Fig. 13 illustrates a simplification of the mass distribution for the double deck screen. The following is a list of assumptions made:

- Each deck of the screen is a distributed parameter system, but can be approximated with $n$ first order lumped parameter systems or components.

- The overflow and underflow mass feed rates $\left(W_{o, i}, W_{t c, i}, W_{c, i}\right.$, and $\left.W_{f, i}\right)$ of each component $i$ are proportional to their mass $\left(M_{o, i}\right.$ and $M_{c, i}$ ) on top of each component $i$ for both the top and bottom deck.

- The proportion of mass split $\left(\alpha_{o}\right.$ and $\alpha_{c}$ ) for each component $i$ on the top and bottom deck is dependent on the particle size distribution of the feed $\left(\sqrt[n]{\frac{W_{o, n}}{W_{o, 0}}}\right.$ and $\left.\sqrt[n]{\frac{W_{t c, n}}{W_{o, 0}}}\right)$.

Using these assumptions, the top and bottom rate of change of mass of component $i$ is given as:

$\frac{d M_{o, i}}{d t}=W_{o, i-1}-\alpha_{o} \frac{M_{o, i}}{\tau_{o}}-\left(1-\alpha_{o}\right) \frac{M_{o, i}}{\tau_{o, c o}}$,

$\frac{d M_{c, i}}{d t}=W_{t c, i-1}+W_{c, i}-\alpha_{c} \frac{M_{c, i}}{\tau_{c}}-\left(1-\alpha_{c}\right) \frac{M_{c, i}}{\tau_{c, f c}}$.

Modelling each mass component $i$ of each deck for a maximum of $n$ components, result in $W_{o, 0}$ being the initial feed into the double-deck screen, $W_{o, n}$ being the final mass feed rate of the oversize material for the top deck and $W_{t c, n}$ being the final mass feed rate of the oversize material for the bottom deck or coarse material. The undersize material of the bottom deck is collected and can be taken as the sum of all underflow mass components (i.e. $\sum_{i=1}^{n} W_{f, i}$ ). The associated variables for this model are described in Table 3.
Table 3

Double-deck screen model variables and descriptions.

\begin{tabular}{|c|c|}
\hline Variable & Description \\
\hline$W_{o, i-1}$ & Mass feed rate of the ore fed into component $i$ on the top deck $(\mathrm{kg} / \mathrm{s})$ \\
\hline$W_{o, i}$ & $\begin{array}{l}\text { Mass feed rate of the ore overflow exiting mass component } i \text { on the } \\
\text { top deck }(\mathrm{kg} / \mathrm{s})\end{array}$ \\
\hline$W_{c, i}$ & $\begin{array}{l}\text { Mass feed rate of the undersized ore exiting mass component } i \text { from } \\
\text { the top deck }(\mathrm{kg} / \mathrm{s})\end{array}$ \\
\hline$M_{o, i}$ & Mass of ore on the top deck for mass component $i(\mathrm{~kg})$ \\
\hline$\alpha_{0}$ & Percentage of mass split on the top deck for mass component $i$ \\
\hline$\tau_{o}$ & $\begin{array}{l}\text { Time taken for ore to be transported over the top deck screen } \\
\text { component } i(\mathrm{~s})\end{array}$ \\
\hline$\tau_{o, c o}$ & $\begin{array}{l}\text { Time taken for ore to be transported through the top deck screen } \\
\text { component } i(\mathrm{~s})\end{array}$ \\
\hline$W_{t c, i-1}$ & $\begin{array}{l}\text { Mass feed rate of the ore fed into component } i \text { on the bottom deck } \\
(\mathrm{kg} / \mathrm{s})\end{array}$ \\
\hline$W_{t c, i}$ & $\begin{array}{l}\text { Mass feed rate of the ore overflow exiting mass component } i \text { on the } \\
\text { bottom deck }(\mathrm{kg} / \mathrm{s})\end{array}$ \\
\hline$W_{f, i}$ & $\begin{array}{l}\text { Mass feed rate of the undersized ore exiting mass component } i \text { from } \\
\text { the bottom deck }(\mathrm{kg} / \mathrm{s})\end{array}$ \\
\hline$M_{c, i}$ & Mass of ore on the bottom deck for mass component $i(\mathrm{~kg})$ \\
\hline$\alpha_{c}$ & Percentage of mass split on the bottom deck for mass component $i$ \\
\hline$\tau_{c}$ & $\begin{array}{l}\text { Time taken for ore to be transported over the bottom deck screen } \\
\text { component } i(\mathrm{~s})\end{array}$ \\
\hline$\tau_{c, f c}$ & $\begin{array}{l}\text { Time taken for ore to be transported through the bottom deck } \\
\text { screen component } i(\mathrm{~s})\end{array}$ \\
\hline
\end{tabular}

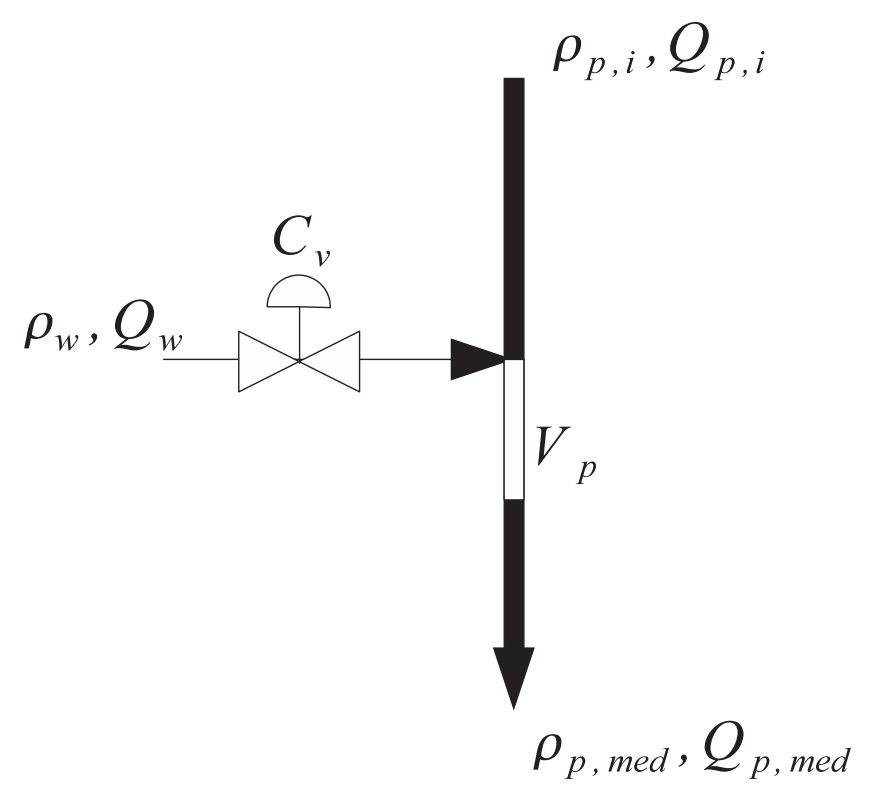

Fig. 14. Simplified representation of water-magnetite in-line mixing.

\subsection{Magnetite medium water addition}

The conservation of overall mass was again used to develop the dynamic model for the addition of water to the medium. Fig. 14 illustrates a simplification of this system. The following is a list of assumptions that were made:

- In-line mixing takes place between the added water $\left(Q_{w}\right)$ and medium $\left(Q_{p, i}\right)$. The effluent is well-mixed within a constant volume $V_{p}$ of the pipe.

- The valve is linear with a constant pressure drop $\Delta p$.

- The volumetric flow rates of the recovered $\left(Q_{p, i}\right)$ and corrected medium $\left(Q_{p, \text { med }}\right)$ is instantaneous before and after a step is introduced in the valve position $\ell_{p}$ (i.e. no valve dynamics).

By assuming a linear valve (where $Q_{w}=C_{v} \frac{\ell_{p}}{100} \sqrt{\frac{\Delta p}{1000}}$ is the flow rate of water through the valve) the following model can be formulated, 
Table 4

Magnetite medium water addition variables and descriptions.

\begin{tabular}{ll}
\hline Variable & Description \\
\hline$\rho_{w}=1000$ & Density of water $\left(\mathrm{kg} / \mathrm{m}^{3}\right)$ \\
$Q_{w}$ & Volumetric flow rate of the water $\left(\mathrm{m}^{3} / \mathrm{s}\right)$ \\
$C_{v}$ & Valve coefficient \\
$\ell_{p}$ & Valve position (\%) \\
$\Delta p$ & Pressure drop over the valve $(\mathrm{kPa})$ \\
$\rho_{p, i}$ & Density of the recovered magnetite medium $\left(\mathrm{kg} / \mathrm{m}^{3}\right)$ \\
$Q_{p, i}$ & Volumetric flow rate of the recovered magnetite medium $\left(\mathrm{m}^{3} / \mathrm{s}\right)$ \\
$\rho_{p, \text { med }}$ & Density of the corrected magnetite medium $\left(\mathrm{kg} / \mathrm{m}^{3}\right)$ \\
$Q_{p, \text { med }}$ & Volumetric flow rate of the corrected magnetite medium $\left(\mathrm{m}^{3} / \mathrm{s}\right)$ \\
$V_{p}$ & Volume required until solution is perfectly mixed $\left(\mathrm{m}^{3}\right)$ \\
\hline
\end{tabular}

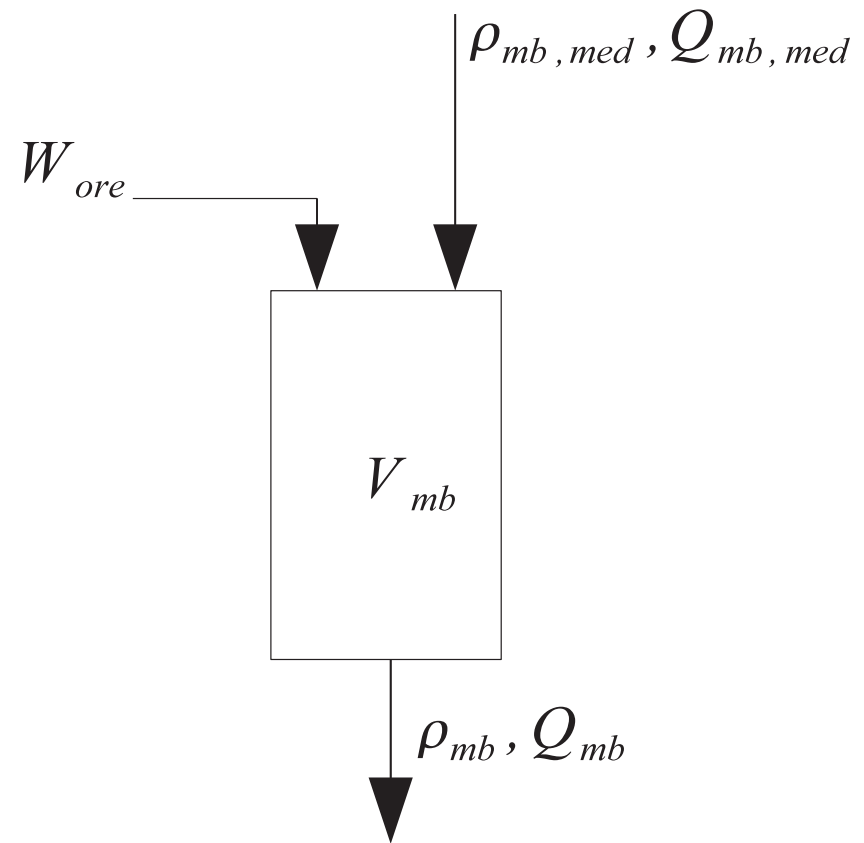

Fig. 15. Simplified representation of a mixing box.

$\frac{d \rho_{p, \text { med }}}{d t}=\frac{-Q_{p, \text { med }}}{V_{p}} \rho_{p, \text { med }}+\frac{1000 K_{p}}{V_{p}} \frac{\ell}{100}+\frac{Q_{p, i}}{V_{p}} \rho_{p, i}$,

where $K_{p}=C_{v} \sqrt{\frac{\Delta p}{1000}}$. The associated variables for this model are described in Table 4.

\subsection{Mixing box}

In developing a model for the mixing box, the conservation of overall mass was used in conjunction with Fig. 15, where the ore is mixed with the medium. The following is a list of assumptions that were made.

- The medium and ore is well-mixed within a constant volume $V_{m b}$.

- The volumetric flow rates of the corrected medium and mix $\left(Q_{m b, m e d}\right.$ and $\left.Q_{m b}\right)$ are instantaneous before and after a step is introduced in the medium density $\left(\rho_{m b, \text { med }}\right)$ or mass feed rate of the ore $\left(W_{\text {ore }}\right)$. The fixed-speed pumping of material and constant mixing box volume result in no rate of change of volume.

The rate of change of density of the mix is given by,

$\frac{d \rho_{m b}}{d t}=\frac{-Q_{m b}}{V_{m b}} \rho_{m b}+\frac{Q_{m b, m e d}}{V_{m b}} \rho_{m b, \text { med }}+\frac{1}{V_{m b}} W_{\text {ore }}$,

with the associated variables as described in Table 5 .
Table 5

Mixing box model variables and descriptions.

\begin{tabular}{ll}
\hline Variable & Description \\
\hline$W_{\text {ore }}$ & Mass feed rate of the ore $(\mathrm{kg} / \mathrm{s})$ \\
$\rho_{m b, m e d}$ & Density of the corrected magnetite medium $\left(\mathrm{kg} / \mathrm{m}^{3}\right)$ \\
$Q_{m b, m e d}$ & Volumetric flow rate of the corrected magnetite medium $\left(\mathrm{m}^{3} / \mathrm{s}\right)$ \\
$\rho_{m b}$ & Density of the mix $\left(\mathrm{kg} / \mathrm{m}^{3}\right)$ \\
$Q_{m b}$ & Volumetric flow rate of the mix $\left(\mathrm{m}^{3} / \mathrm{s}\right)$ \\
$V_{m b}$ & Fixed volume of mixing box $\left(\mathrm{m}^{3}\right)$ \\
\hline
\end{tabular}

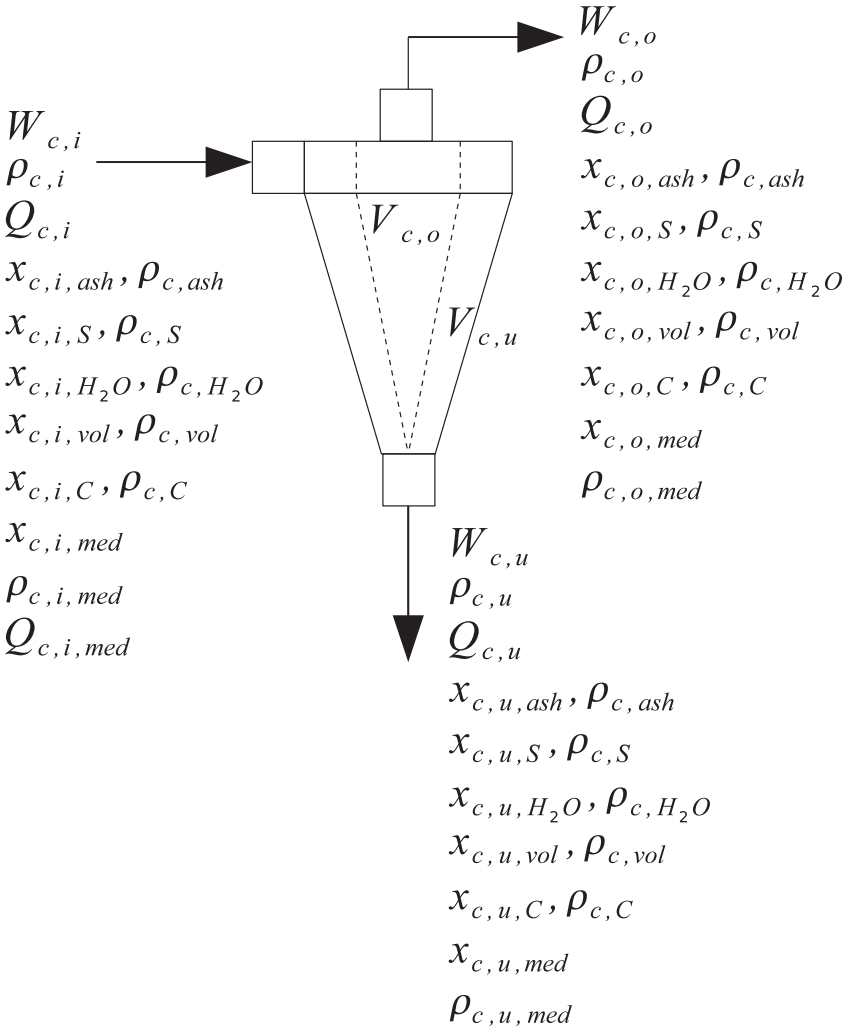

Fig. 16. Simplified representation of a DMC.

\subsection{DMC}

In order to model the throughput of the DMC dynamically, it is necessary to make use of the conservation of overall mass, while the conservation of mass of components is used to model the quality (i.e. ash percentage) of the coal product. A representation of the DMC can be found in Fig. 16, associated variables describing the model being given in Tables 6 and 7 .

The following is a list of assumptions that were made:

- The volume of the mix in the cyclone $\left(V_{c}\right)$ is constant.

- The volumes of the overflow $\left(V_{c, o}\right)$ and underflow $\left(V_{c, u}\right)$ mix in the cyclone and are split at a constant ratio $\alpha$.

- The volumetric flow rates of the feed $\left(Q_{c, i}\right)$, overflow $\left(Q_{c, o}\right)$ and underflow $\left(Q_{c, u}\right)$ are constant before and after a step is introduced in the medium density $\left(\rho_{c, i}\right)$ or feed rate of the ore $\left(W_{c, i}\right)$.

- The volumetric flow rates of the overflow $\left(Q_{c, o}\right)$ and underflow $\left(Q_{c, u}\right)$ are split at a constant ratio $\alpha$.

- Only ash, sulphur, moisture, volatile, medium and fixed carbon components will be considered for the conservation of mass of components in the feed (i.e. $x_{c, i, a s h}+x_{c, i, S}+x_{c, i, H_{2} O}+x_{c, i, v o l}+$ $x_{c, i, m e d}+x_{c, i, c}=1$ ), overflow (i.e. $x_{c, o, a s h}+x_{c, o, S}+x_{c, o, H_{2} O}+x_{c, o, v o l}+$ $x_{c, o, \text { med }}+x_{c, o, c}=1$ ) and underflow (i.e. $x_{c, u, a s h}+x_{c, u, S}+x_{c, u, H_{2} O}+$ $\left.x_{c, u, v o l}+x_{c, u, \text { med }}+x_{c, u, C}=1\right)$. 
Table 6

DMC input variables and descriptions.

\begin{tabular}{|c|c|}
\hline Variable & Description \\
\hline$W_{c, i}$ & Mass feed rate of the feed mix $(\mathrm{kg} / \mathrm{s})$ \\
\hline$\rho_{c, i}$ & Density of the feed mix $\left(\mathrm{kg} / \mathrm{m}^{3}\right)$ \\
\hline$Q_{c, i}$ & Volumetric flow rate of the feed $\operatorname{mix}\left(\mathrm{m}^{3} / \mathrm{s}\right)$ \\
\hline$v_{c, i}$ & Linear velocity of the feed $\operatorname{mix}(\mathrm{m} / \mathrm{s})$ \\
\hline$V_{c}=V_{c, o}+V_{c, u}$ & Volume of the material within the cyclone $\left(\mathrm{m}^{3}\right)$ \\
\hline$\alpha$ & $\begin{array}{l}\text { Overflow and underflow proportionality } \\
\text { constant }\end{array}$ \\
\hline$A_{c}$ & Area of the inlet $\left(\mathrm{m}^{3}\right)$ \\
\hline$R_{c}$ & $\begin{array}{l}\text { Effective radius at which separation takes place } \\
\text { near the spigot }(\mathrm{m})\end{array}$ \\
\hline$d_{c}$ & Average particle size $(\mathrm{m})$ \\
\hline $\begin{array}{l}x_{c, i, a s h}, x_{c, i, S}, x_{c, i, H_{2} O}, x_{c, i, v o l} \\
\quad x_{c, i, C}\end{array}$ & $\begin{array}{l}\text { Percentage ash, sulphur, water, volatiles and } \\
\text { fixed carbon in the feed mix }\end{array}$ \\
\hline$\rho_{c, \text { ash }}, \rho_{c, S}, \rho_{c, H_{2} O}, \rho_{c, v o l}, \rho_{c, C}$ & $\begin{array}{l}\text { Ash, sulphur, water, volatiles and fixed carbon } \\
\text { densities }\left(\mathrm{kg} / \mathrm{m}^{3}\right)\end{array}$ \\
\hline$x_{c, i, m e d}$ & Percentage magnetite in the feed mix \\
\hline$\rho_{c, i, m e d}$ & $\begin{array}{l}\text { Density of the magnetite medium in the feed mix } \\
\left(\mathrm{kg} / \mathrm{m}^{3}\right)\end{array}$ \\
\hline$Q_{c, i, m e d}$ & $\begin{array}{l}\text { Volumetric flow rate of the magnetite medium in } \\
\text { the feed } \mathrm{mix}\left(\mathrm{m}^{3} / \mathrm{s}\right)\end{array}$ \\
\hline
\end{tabular}

Table 7

DMC output variables and descriptions.

\begin{tabular}{|c|c|}
\hline Variable & Description \\
\hline$W_{c, o}$ & Mass feed rate of the overflow $(\mathrm{kg} / \mathrm{s})$ \\
\hline$\rho_{c, o}$ & Density of the overflow $\left(\mathrm{kg} / \mathrm{m}^{3}\right)$ \\
\hline$Q_{c, o}$ & Volumetric flow rate of the overflow $\left(\mathrm{m}^{3} / \mathrm{s}\right)$ \\
\hline$V_{c, o}$ & Volume split of the overflow within the DMC $\left(\mathrm{m}^{3}\right)$ \\
\hline $\begin{array}{l}x_{c, o, a s h}, x_{c, o, S}, x_{c, o, H_{2} O} \\
\quad x_{c, o, v o l}, x_{c, o, C}\end{array}$ & $\begin{array}{l}\text { Percentage ash, sulphur, water, volatiles and fixed } \\
\text { carbon in the overflow }\end{array}$ \\
\hline$x_{c, o, \text { med }}$ & Percentage magnetite medium in the overflow \\
\hline$\rho_{c, o, \text { med }}$ & $\begin{array}{l}\text { Density of the magnetite medium in the overflow }(\mathrm{kg} / \\
\left.\mathrm{m}^{3}\right)\end{array}$ \\
\hline$W_{c, u}$ & Mass feed rate of the underflow $(\mathrm{kg} / \mathrm{s})$ \\
\hline$\rho_{c, u}$ & Density of the underflow $\left(\mathrm{kg} / \mathrm{m}^{3}\right)$ \\
\hline$Q_{c, u}$ & Volumetric flow rate of the underflow $\left(\mathrm{m}^{3} / \mathrm{s}\right)$ \\
\hline$V_{c, u}$ & Volume split of the underflow within the DMC $\left(\mathrm{m}^{3}\right)$ \\
\hline $\begin{array}{l}x_{c, u, a s h}, x_{c, u, S}, x_{c, u, H_{2} O} \\
\quad x_{c, u, v o l}, x_{c, u, C}\end{array}$ & $\begin{array}{l}\text { Percentage ash, sulphur, water, volatiles and fixed } \\
\text { carbon in the underflow }\end{array}$ \\
\hline$x_{c, u, \text { med }}$ & Percentage magnetite medium in the underflow \\
\hline$\rho_{c, u, \text { med }}$ & $\begin{array}{l}\text { Density of the magnetite medium in the underflow }(\mathrm{kg} / \\
\left.\mathrm{m}^{3}\right)\end{array}$ \\
\hline$K_{c, o}$ & Proportionality constant for the overflow $\left(\mathrm{m}^{3} / \mathrm{s}\right)$ \\
\hline$K_{c, u}$ & Proportionality constant for the underflow $\left(\mathrm{m}^{3} / \mathrm{s}\right)$ \\
\hline$K_{c, o, a s h}$ & Proportionality constant for the ash overflow $\left(\mathrm{m}^{3} / \mathrm{kg} \mathrm{s}\right)$ \\
\hline$K_{c, u, a s h}$ & Proportionality constant for the ash underflow $\left(\mathrm{m}^{3} / \mathrm{kg} \mathrm{s}\right)$ \\
\hline$K_{c, o, S}$ & $\begin{array}{l}\text { Proportionality constant for the sulphur overflow }\left(\mathrm{m}^{3} /\right. \\
\mathrm{kg} \mathrm{s})\end{array}$ \\
\hline$K_{c, u, S}$ & $\begin{array}{l}\text { Proportionality constant for the sulphur underflow }\left(\mathrm{m}^{3} /\right. \\
\mathrm{kg} \mathrm{s})\end{array}$ \\
\hline$K_{c, o, H_{2} \mathrm{O}}$ & $\begin{array}{l}\text { Proportionality constant for the moisture overflow }\left(\mathrm{m}^{3} /\right. \\
\mathrm{kg} \mathrm{s})\end{array}$ \\
\hline$K_{c, u, H_{2} O}$ & $\begin{array}{l}\text { Proportionality constant for the moisture underflow } \\
\left(\mathrm{m}^{3} / \mathrm{kg} \mathrm{s}\right)\end{array}$ \\
\hline$K_{c, o, v o l}$ & $\begin{array}{l}\text { Proportionality constant for the volatile overflow }\left(\mathrm{m}^{3} /\right. \\
\mathrm{kg} \mathrm{s})\end{array}$ \\
\hline$K_{c, u, v o l}$ & $\begin{array}{l}\text { Proportionality constant for the volatile underflow }\left(\mathrm{m}^{3} /\right. \\
\mathrm{kg} \mathrm{s})\end{array}$ \\
\hline$K_{c, o, \text { med }}$ & $\begin{array}{l}\text { Proportionality constant for the magnetite medium } \\
\text { overflow }\left(\mathrm{m}^{3} / \mathrm{kg} \mathrm{s}\right)\end{array}$ \\
\hline$K_{c, u, \text { med }}$ & $\begin{array}{l}\text { Proportionality constant for the magnetite medium } \\
\text { underflow }\left(\mathrm{m}^{3} / \mathrm{kg} \mathrm{s}\right)\end{array}$ \\
\hline$K_{c, o, C}$ & $\begin{array}{l}\text { Proportionality constant for the fixed carbon overflow } \\
\left(\mathrm{m}^{3} / \mathrm{kg} \mathrm{s}\right)\end{array}$ \\
\hline$K_{c, u, c}$ & $\begin{array}{l}\text { Proportionality constant for the fixed carbon underflow } \\
\left(\mathrm{m}^{3} / \mathrm{kg} \mathrm{s}\right)\end{array}$ \\
\hline
\end{tabular}

- The rates of change in mass for the overflow $\left(\frac{d W_{c, o}}{d t}\right)$ and underflow $\left(\frac{d W_{c, u}}{d t}\right)$ are proportional to the difference in their densities $\left(\rho_{c, o}\right.$ and $\left.\rho_{c, u}\right)$ to the magnetite medium density $\left(\rho_{c, i, m e d}\right)$, the acceleration due to a centrifugal force $\left(\frac{v_{c, i}^{2}}{R_{c}}\right)$ and the percentage of either ash or carbon in the feed $\left(x_{c, i, a s h}\right.$ or $\left.x_{c, i, C}\right)$.

- The rates of change in percentages of components to the overflow $\left(\frac{d x_{c, o, a s h}}{d t}, \frac{d x_{c, 0, S}}{d t}, \frac{d x_{c, 0, H_{2} O} O}{d t}, \frac{d x_{c, 0, v o l}}{d t}\right.$ and $\left.\frac{d x_{c, o, C}}{d t}\right)$ and underflow $\left(\frac{d x_{c, u, a s h}}{d t}, \frac{d x_{c, u, s}}{d t}, \frac{d x_{c, u, H_{2}} o}{d t}, \frac{d x_{c, u, v o l}}{d t}\right.$ and $\left.\frac{d x_{c, u, c}}{d t}\right)$ are proportional to the difference in their component densities ( $\rho_{c, a s h}, \rho_{c, S}, \rho_{c, H_{2} O}, \rho_{c, v o l}$ and $\left.\rho_{c, C}\right)$ to the magnetite medium density $\left(\rho_{c, i, m e d}\right)$, the difference in their component percentages $\left(x_{c, o, a s h}, x_{c, o, S}, x_{c, o, H_{2} O}, x_{c, o, v o l}, x_{c, o, C}\right.$, $x_{c, u, a s h}, x_{c, u, S}, x_{c, u, H_{2} O}, x_{c, u, v o l}$ and $\left.x_{c, u, C}\right)$ to their corresponding feed percentages $\left(x_{c, i, a s h}, x_{c, i, S}, x_{c, i, H_{2} O}, x_{c, i, v o l}\right.$ and $\left.x_{c, i, C}\right)$, the acceleration due to a centrifugal force $\left(\frac{v_{c, i}^{2}}{R_{c}}\right)$ and inversely proportional to the average particle size of the ore $\left(d_{c}\right)$.

In order to simplify the model, it is assumed that the volumetric flow is at steady state (i.e. $Q_{c, i}=Q_{c, o}+Q_{c, u}$ ) and that the overflow and underflow are volumetrically split by a proportion $\alpha$. This means that $Q_{c, o}=\alpha Q_{c, u}$ (i.e. $Q_{c, o}=\frac{\alpha Q_{c, i}}{1+\alpha}$ and $Q_{c, u}=\frac{Q_{c, i}}{1+\alpha}$ ). Similarly, it is assumed that the cyclone volume $V_{c}$ is separated according to the same split proportion $\alpha$ as in the volumetric feed flow (i.e. $V_{c, o}=\frac{\alpha V_{c}}{1+\alpha}$ and $\left.V_{c, u}=\frac{V_{c}}{1+\alpha}\right)$. By using the overall conservation of mass the following relationship describing the DMC can be developed:

$V_{c, o} \frac{d \rho_{c, o}}{d t}+V_{c, u} \frac{d \rho_{c, u}}{d t}=W_{c, i}-Q_{c, o} \rho_{c, o}-Q_{c, u} \rho_{c, u}$

The concept of the acceleration due to the centrifugal force within the cyclone can be used to model the effects of the dynamics of the density response for the cyclone. The centrifugal force indicates that the rates of change in mass for the overflow and underflow are proportional to their differences in densities to the medium density. The percentage of ash or carbon will also influence the dynamics of the cyclone and can yield the following relationship:

$V_{c, o} \frac{d \rho_{c, o}}{d t}=K_{c, o}\left(\rho_{c, i, m e d}-\rho_{c, o}\right) x_{c, i, c}$,

$V_{c, u} \frac{d \rho_{c, u}}{d t}=K_{c, u}\left(\rho_{c, i, m e d}-\rho_{c, u}\right) x_{c, i, a s h}$,

where $\frac{v_{c, i}^{2}}{R_{c}}=\frac{Q_{c, i}^{2}}{A_{c}^{2} R_{c}}$ is the centrifugal acceleration (where $A_{c}$ is the crosssectional area of the inlet and $R_{c}$ is the effective radius of the cyclone near the spigot where most of the separation takes place). By combining Eq. (6) with Eqs. (7) and (8), the overflow and underflow density transfer functions for the DMC can be developed.

Similarly, the conservation of mass of each component within the ore that is being beneficiated can be determined. The components that were used in this model include ash, sulphur, moisture, medium and carbon. This results in the following dynamic mass balances:

$$
\begin{aligned}
& V_{c, o} \rho_{c, o} \frac{d x_{c, o, a s h}}{d t}+V_{c, o} x_{c, o, a s h} \frac{d \rho_{c, o}}{d t}+V_{c, u} \rho_{c, u} \frac{d x_{c, u, a s h}}{d t}+V_{c, u} x_{c, u, u s h} \frac{d \rho_{c, u}}{d t} \\
& =W_{c, i} x_{c, i, a s h}-Q_{c, o} \rho_{c, o} x_{c, o, a s h}-Q_{c, u} \rho_{c, u} x_{c, u, a s h} \\
& V_{c, o} \rho_{c, o} \frac{d x_{c, o, S}}{d t}+V_{c, o} x_{c, o, S} \frac{d \rho_{c, o}}{d t}+V_{c, u} \rho_{c, u} \frac{d x_{c, u, S}}{d t}+V_{c, u} x_{c, u, S} \frac{d \rho_{c, u}}{d t} \\
& =W_{c, i} x_{c, i, S}-Q_{c, o} \rho_{c, o} x_{c, o, S}-Q_{c, u} \rho_{c, u} x_{c, u, S}
\end{aligned}
$$

$V_{c, o} \rho_{c, o} \frac{d x_{c, o, H_{2} O}}{d t}+V_{c, o} x_{c, o, H_{2} O} \frac{d \rho_{c, o}}{d t}+V_{c, u} \rho_{c, u} \frac{d x_{c, u, H_{2} O}}{d t}+V_{c, u} x_{c, u, H_{2} O} \frac{d \rho_{c, u}}{d t}$
$=W_{c, i} x_{c, i H_{2} O}-Q_{c, o} \rho_{c, o} x_{c, o} H_{2} O-Q_{c, u} \rho_{c, u} x_{c, u H_{2} O,}$

$$
=W_{c, i} x_{c, i, H_{2} O}-Q_{c, o} \rho_{c, o} x_{c, o, H_{2} O}-Q_{c, u} \rho_{c, u} x_{c, u, H_{2} O},
$$

$V_{c, o} \rho_{c, o} \frac{d x_{c, o, v o l}}{d t}+V_{c, o} x_{c, o, v o l} \frac{d \rho_{c, o}}{d t}+V_{c, u} \rho_{c, u} \frac{d x_{c, u, v o l}}{d t}+V_{c, u} x_{c, u, v o l} \frac{d \rho_{c, u}}{d t}$

$=W_{c, i} x_{c, i, v o l}-Q_{c, o} \rho_{c, o} x_{c, o, v o l}-Q_{c, u} \rho_{c, u} x_{c, u, v o l}$ 


$$
\begin{aligned}
& V_{c, o} \rho_{c, o} \frac{d x_{c, o, \text { med }}}{d t}+V_{c, o} x_{c, o, \text { med }} \frac{d \rho_{c, o}}{d t}+V_{c, u} \rho_{c, u} \frac{d x_{c, u, \text { med }}}{d t}+V_{c, u} x_{c, u, \text { med }} \frac{d \rho_{c, u}}{d t} \\
& =W_{c, i} x_{c, i, m e d}-Q_{c, o} \rho_{c, o} x_{c, o, \text { med }}-Q_{c, u} \rho_{c, u} x_{c, u, \text { med }}, \\
& V_{c, o} \rho_{c, o} \frac{d x_{c, o, C}}{d t}+V_{c, o} x_{c, o, c} \frac{d \rho_{c, o}}{d t}+V_{c, u} \rho_{c, u} \frac{d x_{c, u, C}}{d t}+V_{c, u} x_{c, u, C} \frac{d \rho_{c, u}}{d t} \\
& =W_{c, i} x_{c, i, C}-Q_{c, o} \rho_{c, o} x_{c, o, c}-Q_{c, u} \rho_{c, u} x_{c, u, c} .
\end{aligned}
$$

To develop solutions for the rates of change in component percentages, some assumptions have to be made. The rates of change in component percentages for the overflow and underflow are assumed to be proportional to the difference in their component densities to the medium density. It is also assumed that the rates of change in component percentages are proportional to the difference in their component percentages to their corresponding feed percentages and their acceleration due to gravity. The rates of change in component percentages are also assumed to be inversely proportional to the average particle size of the ore. This will yield the following relationships:

$$
\begin{aligned}
& \frac{d x_{c, o, a s h}}{d t}=K_{c, o, a s h}\left(\rho_{c, i, m e d}-\rho_{a s h}\right)\left(x_{c, i, a s h}-x_{c, o, a s h}\right), \\
& \frac{d x_{c, u, a s h}}{d t}=K_{c, u, a s h}\left(\rho_{a s h}-\rho_{c, i, m e d}\right)\left(x_{c, i, a s h}-x_{c, u, a s h}\right), \\
& \frac{d x_{c, o, S}}{d t}=K_{c, o, S}\left(\rho_{c, i, m e d}-\rho_{S}\right)\left(x_{c, i, S}-x_{c, o, S}\right), \\
& \frac{d x_{c, u, S}}{d t}=K_{c, u, S}\left(\rho_{S}-\rho_{c, i, m e d}\right)\left(x_{c, i, S}-x_{c, u, S}\right), \\
& \frac{d x_{c, o, H_{2} O}}{d t}=K_{c, o, H_{2} O}\left(\rho_{c, i, m e d}-\rho_{H_{2} O}\right)\left(x_{c, i, H_{2} O}-x_{c, o, H_{2} O}\right), \\
& \frac{d x_{c, u, H_{2} O}}{d t}=K_{c, u, H_{2} O}\left(\rho_{H_{2} O}-\rho_{c, i, m e d}\right)\left(x_{c, i, H_{2} O}-x_{c, u, H_{2} O}\right), \\
& \frac{d x_{c, o, v o l}}{d t}=K_{c, o, v o l}\left(\rho_{c, i, m e d}-\rho_{v o l}\right)\left(x_{c, i, v o l}-x_{c, o, v o l}\right), \\
& \frac{d x_{c, u, v o l}}{d t}=K_{c, u, v o l}\left(\rho_{v o l}-\rho_{c, i, m e d}\right)\left(x_{c, i, v o l}-x_{c, i, u, v o l}\right), \\
& \frac{d x_{c, o, m e d}}{d t}=K_{c, o, \text { med }}\left(\rho_{c, i, m e d}-\rho_{c, o, m e d}\right)\left(x_{c, i, m e d}-x_{c, o, m e d}\right), \\
& \frac{d x_{c, u, m e d}}{d t}=K_{c, u, \text { med }}\left(\rho_{c, u, \text { med }}-\rho_{c, i, m e d}\right)\left(x_{c, i, m e d}-x_{c, u, \text { med }}\right), \\
& \frac{d x_{c, o, C}}{d t}=K_{c, o, C}\left(\rho_{c, i, m e d}-\rho_{C}\right)\left(x_{c, i, C}-x_{c, o, C}\right), \\
& \frac{d x_{c, u, C}}{d t}=K_{c, u, C}\left(\rho_{C}-\rho_{c, i, m e d}\right)\left(x_{c, i, C}-x_{c, u, C}\right) .
\end{aligned}
$$

In the case of the percentage of magnetite in Eqs. (23) and (24), the difference between the overflow and underflow medium density and the feed medium density is used.

By using the equations in this section, a non-linear model of the DMC can be derived.

\subsection{Magnetite make-up corrected medium tank}

Fig. 17 illustrates the variables involved in the corrected medium tank model as defined in Table 8. The following is a list of assumptions that were made:

- The volumetric flow rates of the recovered medium $\left(Q_{t, m e d}\right)$, make-up medium $\left(Q_{t, d i s}\right)$ and corrected medium $\left(Q_{t}\right)$ are instantaneous before and after a step is introduced in the recovered medium density $\left(\rho_{t, \text { med }}\right)$ or make-up medium density $\left(\rho_{t, \text { dis }}\right)$.

- The effective area of the corrected medium tank $\left(A_{t}\right)$ does not change with a change in height of the medium $\left(h_{t}\right)$ in the corrected medium tank.

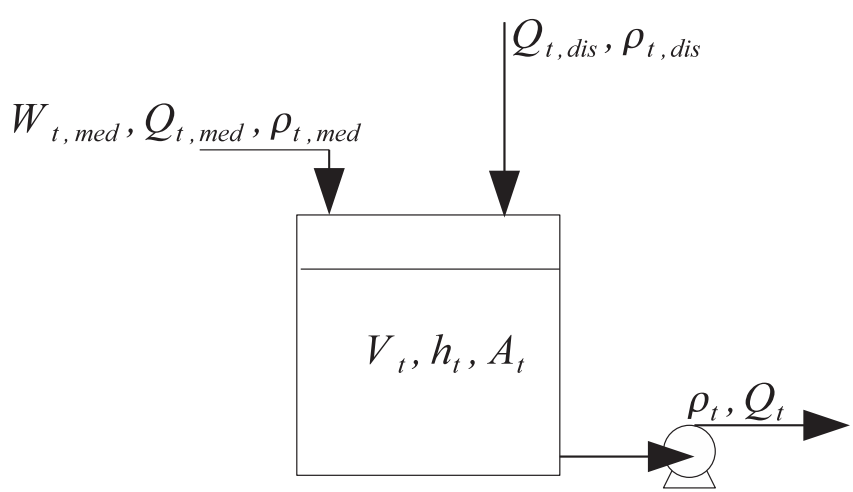

Fig. 17. Simplified representation of a corrected medium make-up tank.

Table 8

Corrected medium tank variables and descriptions.

\begin{tabular}{ll}
\hline Variable & Description \\
\hline$W_{t, \text { med }}$ & Mass feed rate of the magnetite medium recovered $(\mathrm{kg} / \mathrm{s})$ \\
$\rho_{t, \text { med }}$ & Density of the magnetite medium recovered $\left(\mathrm{kg} / \mathrm{m}^{3}\right)$ \\
$Q_{t, \text { med }}$ & Volumetric flow rate of the magnetite medium recovered $\left(\mathrm{m}^{3} / \mathrm{s}\right)$ \\
$\rho_{t, \text { dis }}$ & Density of the magnetite make-up medium disturbance $\left(\mathrm{kg} / \mathrm{m}^{3}\right)$ \\
$Q_{t, \text { dis }}$ & Volumetric flow rate of the magnetite make-up medium \\
& disturbance $\left(\mathrm{m}^{3} / \mathrm{s}\right)$ \\
$\rho_{t}$ & Density of the corrected medium $\left(\mathrm{kg} / \mathrm{m}^{3}\right)$ \\
$Q_{t}$ & Volumetric flow rate of the corrected medium $\left(\mathrm{m}^{3} / \mathrm{s}\right)$ \\
$V_{t}$ & $\begin{array}{l}\text { Volume of the magnetite medium in the corrected medium tank } \\
\left(\mathrm{m}^{3}\right)\end{array}$ \\
$h_{t}$ & $\begin{array}{l}\text { Height of the magnetite medium in the corrected medium tank } \\
\text { (m) }\end{array}$ \\
$h_{t, \text { max }}$ & $\begin{array}{l}\text { Maximum height of the magnetite medium in the corrected } \\
A_{t}\end{array}$ \\
\hline
\end{tabular}

By using the conservation of overall mass, the following relationship for the tank can be determined:

$A_{t} h_{t} \frac{d \rho_{t}}{d t}+A_{t} \rho_{t} \frac{d h_{t}}{d t}=Q_{t, \text { med }} \rho_{t, \text { med }}+Q_{t, \text { dis }} \rho_{t, \text { dis }}-Q_{t} \rho_{t}$,

where the rate of change in height of solution in the tank can be expressed by using the conservation of volumetric flow,

$A_{t} \frac{d h_{t}}{d t}=Q_{t, \text { med }}+Q_{t, d i s}-Q_{t}$.

\section{Parameter estimation and validation procedure}

Performing an industrial experiment on a DMS plant makes it possible to illustrate the accuracy of the models that have been developed by comparing the output of the models to the actual measured output of the plant in response to actual measured plant manipulated variables (Fig. 18). The correlation of the plant $(y)$ and model output $(\hat{y})$ can then be computed to ascertain the accuracy of the model.

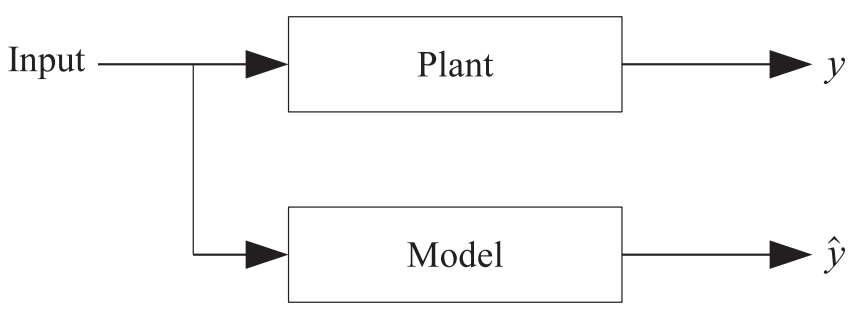

Fig. 18. Comparison of a plant model to an actual plant output 
It is possible for a non-linear DMC model that there may be different solutions for the same set of input-output data sets. Xia and Moog (2003) have developed a technique that allows the inputoutput data sets for a non-linear dynamic model to be mapped uniquely to the parameters defining the system. The number of higher order derivatives required in the identification process make it possible to determine how many measurements of the input and output variables are required to calculate the actual values of the parameters that define the model.

\subsection{Parameter identifiability}

Since the ash component equations (Eqs. (9), (15) and (16)) are similar to those of the other mass components in Section 3.5, it is possible to simplify the identification of the DMC by only considering ash. If the ash component proves to be identifiable, the same will apply for the other components. In order to ensure that the DMC non-linear ash component model is identifiable, it is necessary to assume that certain parameters can be measured to a high degree of accuracy or assumed constant.

The volume $V_{c}$ of the DMC can be measured or calculated to a relatively high degree of accuracy. The volumetric flow rate $Q_{c, i}$ into the DMC can be assumed to be a constant, as the DMC is normally fed by a fixed-speed pump. Other parameters, such as the crosssectional area of the feed inlet $\left(A_{c}\right)$ and the effective radius at the spigot $\left(R_{c}\right)$, are also known. The particle density of ash $\left(\rho_{a s h}\right)$ is a physical property and can be assumed to be known.

By only considering the parameters $\alpha, K_{c, u}, K_{c, u, a s h}$ and $x_{c, i, a s h}$ in the identifiability process, the variables $\mathbf{x}=\left[\begin{array}{c}x_{1} \\ x_{2} \\ x_{3} \\ x_{4}\end{array}\right]=\left[\begin{array}{c}\rho_{c, o} \\ \rho_{c, u} \\ x_{c, o, a s h} \\ x_{c, u, a s h}\end{array}\right]$, $\boldsymbol{\theta}=\left[\begin{array}{c}\alpha \\ K_{c, u} \\ K_{c, u, a s h} \\ x_{c, i, a s h}\end{array}\right]$ and $\mathbf{u}=\left[\begin{array}{c}u_{1} \\ u_{2}\end{array}\right]=\left[\begin{array}{c}W_{c, i} \\ \rho_{c, i, m e d}\end{array}\right]$ can be assigned. Complete observability (observing the state of a system from output measurements) in the output is defined as $\mathbf{y}=\mathbf{h}(\mathbf{t}, \mathbf{x}, \boldsymbol{\theta}, \mathbf{u})$. As a result the state-space representation $\dot{\mathbf{x}}=\mathbf{f}(\mathbf{t}, \mathbf{x}, \boldsymbol{\theta}, \mathbf{u})$ is as follows:

$$
\begin{aligned}
\dot{x}_{1}= & \frac{1+\alpha}{\alpha V_{c}} u_{1}-\frac{Q_{c, i}}{V_{c}} x_{1}-\frac{Q_{c, i}}{\alpha V_{c}} x_{2}-\frac{1+\alpha}{\alpha V_{c}} K_{c, u}\left(x_{2}-u_{2}\right) \\
& \times \frac{Q_{c, i}^{2}}{A_{c}^{2} R_{c}} x_{c, i, a s h},
\end{aligned}
$$

$$
\dot{x}_{2}=\frac{1+\alpha}{V_{c}} K_{c, u}\left(x_{2}-u_{2}\right) \frac{Q_{c, i}^{2}}{A_{c}^{2} R_{c}} x_{c, i, a s h}
$$

$$
\begin{aligned}
\dot{x}_{3}= & \left(\frac{1}{x_{3}}\right)\left[\frac{1+\alpha}{\alpha V_{c}} u_{1} x_{c, i, a s h}-\frac{Q_{c, i}}{V_{c}} x_{1} x_{3}-\frac{Q_{c, i}}{\alpha V_{c}} x_{2} x_{3}\right. \\
& -x_{3}\left(\frac{1+\alpha}{\alpha V_{c}} u_{1}-\frac{Q_{c, i}}{V_{c}} x_{1}-\frac{Q_{c, i}}{\alpha V_{c}} x_{2}-\frac{1+\alpha}{\alpha V_{c}} K_{c, u}\left(x_{2}-u_{2}\right) \frac{Q_{c, i}^{2}}{A_{c}^{2} R_{c}} x_{c, i, a s h}\right) \\
& -\frac{1}{\alpha} x_{2} K_{c, u, a s h}\left(\rho_{c, a s h}-u_{2}\right) \frac{Q_{c, i}^{2}}{A_{c}^{2} R_{c} d_{c}}\left(x_{c, i, a s h}-x_{4}\right) \\
& \left.-\frac{1}{\alpha} x_{4}\left(\frac{1+\alpha}{V_{c}} K_{c, u}\left(x_{2}-u_{2}\right) \frac{Q_{c, i}^{2}}{A_{c}^{2} R_{c}} x_{c, i, a s h}\right)\right]
\end{aligned}
$$

$\dot{x}_{4}=K_{c, u, a s h}\left(\rho_{c, a s h}-u_{2}\right) \frac{Q_{c, i}^{2}}{A_{c}^{2} R_{c} d_{c}}\left(x_{c, i, a s h}-x_{4}\right)$.

Xia and Moog (2003) indicate that a system is algebraically identifiable if there exists a $T>0$, a positive integer $k$ and a meromorphic function $\Phi: R^{q} \times R^{(k+1) m} \times R^{(k+1) p} \rightarrow R^{q}$ such that $\operatorname{det} \frac{\partial \Phi}{\partial \theta} \neq 0$ and
$\Phi\left(\theta, u, \dot{u}, \ldots, u^{(k)}, y, \dot{y}, \ldots, y^{(k)}\right)=0$ hold $\quad$ on $\quad[0, T] \forall\left(\theta, u, \dot{u}, \ldots, u^{(k)}\right.$, $\left.y, \dot{y}, \ldots, y^{(k)}\right)$ where $\left(\theta, x_{0}, u\right)$ belong to an open and dense subset of $R^{q} \times R^{q} \times C_{u}^{N}[0, T] . C_{u}^{N}[0, T]$ denotes the set of all admissible inputs (on $[0, T]$ ) that have continuous derivatives up to the order $N$. $u, \dot{u}, \ldots, u^{(k)}$ and $y, \dot{y}, \ldots, y^{(k)}$ are the derivatives of the input $u(t)$ and output $y\left(t, \theta, x_{0}, u\right) ; u(t) \in C^{k}[0, T]$.

By defining $\Phi$ as the difference between the first time derivative of the output $\left(\frac{\partial \mathbf{h}(\mathbf{t}, \mathbf{x}, \theta, \mathbf{u})}{\partial t}\right)$ and the state derivative $(\dot{\mathbf{x}})$, the Jacobian $\frac{\partial \Phi}{\partial \boldsymbol{\theta}}$ for the DMC state-space system (Eqs. (29)-(32)) has a rank of 4. This allows a unique solution for the parameters in $\boldsymbol{\theta}$ for the DMC to be determined. This can be achieved by using measurements from inputs and outputs based on the functions $\rho_{c, o}, \dot{\rho}_{c, o}$, $\rho_{c, u}, \dot{\rho}_{c, u}, x_{c, o, a s h}, \dot{x}_{c, o, a s h}, x_{c, u, a s h}, \dot{x}_{c, u, a s h}, W_{c, i}$ and $\rho_{c, i, m e d}$. The four parameters $(\boldsymbol{\theta})$ are therefore algebraically identifiable and can therefore be estimated uniquely. In order to estimate these parameters, at least two measurements of each state (i.e. $\rho_{c, o}, \rho_{c, u}, x_{c, o, a s h}$ and $\left.x_{c, u, a s h}\right)$ will be required and at least one measurement of $W_{c, i}$ and $\rho_{c, i, m e d}$ will be necessary.

\subsection{Parameter estimation and validation}

System identification (Ljung, 1987) means that once a set of candidate models is obtained, it is necessary to assess the candidate models using the available data.

Ljung (1987) supposes that a set of candidate models has been selected as a model structure $\mathscr{M}$ and is parameterised with particular models $\mathscr{M}(\theta)$ using parameter vector $\theta \in \mathbf{D}_{\mathscr{M}} \subset \mathbf{R}^{\mathbf{d}}$. The mapping of the data $\mathbf{Z}^{N}$ where $\mathbf{Z}^{\mathbf{N}}=[\mathbf{y}(1), \mathbf{u}(1), \mathbf{y}(2), \mathbf{u}(2), \ldots, \mathbf{y}(\mathbf{N}), \mathbf{u}(\mathbf{N})]$, to the set $D_{\mathscr{M}}$,

$\mathbf{Z}^{\mathbf{N}} \rightarrow \hat{\theta}_{\mathbf{N}} \in \mathbf{D}_{\mathscr{M}}$,

is known as a parameter estimation method. In order for a model to predict a system output, a prediction error,

$\epsilon\left(t, \theta_{*}\right)=y(t)-\hat{y}\left(t \mid \theta_{*}\right)$,

calculated using a certain model $\mathscr{M}\left(\theta_{*}\right)$ must be computed for $t=1,2, \ldots, N$ for a known data set $\mathbf{Z}^{\mathbf{N}}$. Ljung (1987) indicates that the prediction error $\left(\epsilon\left(t, \theta^{*}\right)\right)$ has similar properties for non-linear state-space models, except that Eq. (34) is a non-linear function of past data. Parameter estimation is described as the process where $\hat{\theta}_{N}$ is selected so that the prediction error (Eq. (34)) becomes as small as possible (Ljung, 1987).

Ljung (1987) mentions two approaches to determine the quality of the model. These are the scalar-valued norm approach and the approach that demands that $\epsilon\left(t, \hat{\theta}_{N}\right)$ is uncorrelated with a given data sequence. The scalar-valued norm that measures the size of $\epsilon$ is used for the parameter estimation of the equipment models for this paper to ensure consistency in the selection of model parameter values.

The norm,

$V_{N}\left(\boldsymbol{\theta}, \mathbf{Z}^{\mathbf{N}}\right)=\frac{1}{\mathbf{N}} \sum_{\mathbf{t}=1}^{\mathbf{N}} \ell(\epsilon(\mathbf{t}, \theta))$,

with $\ell(\cdot)$ as a positive scalar-valued function can be used to determine the quality of the model $\mathscr{M}(\boldsymbol{\theta})$. The minimisation of Eq. (35),

$\hat{\theta}_{N}=\hat{\theta}_{N}\left(\mathbf{Z}^{\mathbf{N}}\right)=\arg \min _{\boldsymbol{\theta} \in \mathbf{D}_{\mathscr{M}}} \mathbf{V}_{\mathbf{N}}\left(\theta, \mathbf{Z}^{\mathbf{N}}\right)$,

allows the estimation of $\hat{\theta}_{N}$. The procedures used to estimate $\theta$ are referred to as prediction-error identification methods (PEM). For this paper $\ell(\cdot)$ is chosen as the quadratic norm (Ljung, 1987),

$\ell(\epsilon)=\frac{1}{2} \epsilon^{2}$

By applying Eq. (36) it is possible to obtain a PEM to estimate model parameters by iteration. A process illustrated in Fig. 19 (Rath- 


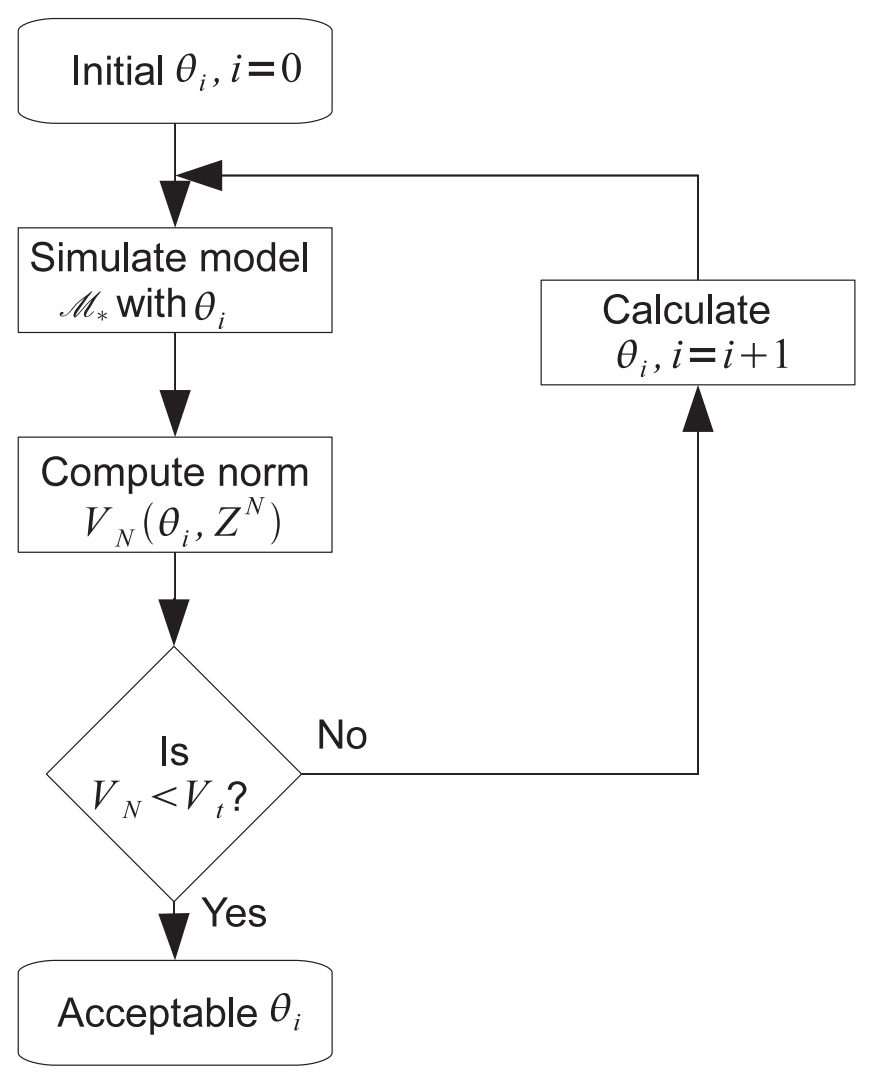

Fig. 19. Parameter estimation iteration (Rathaba, 2004). $\mathscr{M}_{*}$ refers to the different equipment models that have been developed in Section 3.

Table 9

Equipment models that can be used in place of $\mathscr{M}_{*}$ in Fig. 19.

\begin{tabular}{ll}
\hline $\mathscr{M}_{*}$ & Eq. (s) \\
\hline Single-deck screen & $(1)$ \\
Double-deck screen & $(2)$ and (3) \\
Magnetite medium water addition & $(4)$ \\
Mixing box & $(5)$ \\
DMC & $(6)-(26)$ \\
Magnetite make-up corrected medium tank & $(27)$ and (28) \\
\hline
\end{tabular}

aba, 2004) can be used to ensure that the model parameters define the actual process to a certain degree of accuracy $V_{t}$. By computing the norm (Eq. (35)) and iteratively changing the model parameters $\left(\theta_{N}\right)$, it is possible to find a model that fits the data to a specific accuracy. The process in Fig. 19 can be applied to the different equipment models $\left(\mathscr{M}_{*}\right)$ developed in Section 3. Table 9 indicates the different equipment models that can be used in place of $\mathscr{M}_{*}$.

Table 10 shows the model parameter values determined by using the PEM for the dynamic equipment models that have been developed. In the case of the screens, the proportion of mass split describing the various overflows and underflows are estimated by using measured input $\left(W_{i}\right)$ and output $\left(W_{f}^{\prime}\right.$ and $W_{o}$ ) feed rate streams. This is because of the variability of the particle size distributions of the ore from the drilling and blasting in the mining operation. By assuming that each screen deck can be modelled as 10 first-order linear system distributions in series, the 10th root of each mass split parameter is calculated.

\subsection{Industrial experiment test case}

In order to verify the model simulations it was necessary to perform a specific setpoint change on the DMS plant while taking measurements of the relevant inputs and outputs.
Table 10

Model parameter estimates.

\begin{tabular}{|c|c|c|}
\hline Equipment model & Parameter & Estimate \\
\hline \multirow[t]{3}{*}{ Single-deck screen } & $\alpha_{f}$ & $\sqrt[10]{\frac{W_{f}^{\prime}}{W_{i}}}$ \\
\hline & $\tau_{f}$ & $0.7(\mathrm{~s})$ \\
\hline & $\tau_{f, u f}$ & $6.3(\mathrm{~s})$ \\
\hline \multirow[t]{6}{*}{ Double-deck screen } & $\alpha_{o}$ & $\sqrt[10]{\frac{W_{o}}{W_{i}}}$ \\
\hline & $\tau_{o}$ & $0.7(\mathrm{~s})$ \\
\hline & $\tau_{o, c o}$ & $0.7(\mathrm{~s})$ \\
\hline & $\alpha_{c}$ & $\sqrt[10]{\frac{W_{c}^{\prime}}{W_{i}}}$ \\
\hline & $\tau_{c}$ & $0.7(\mathrm{~s})$ \\
\hline & $\tau_{c, f c}$ & $1.4(\mathrm{~s})$ \\
\hline \multirow{4}{*}{$\begin{array}{l}\text { Magnetite medium } \\
\text { water addition }\end{array}$} & $Q_{p, i}$ & $0.495\left(\mathrm{~m}^{3} / \mathrm{s}\right)$ \\
\hline & $Q_{p, \text { med }}$ & $0.495\left(\mathrm{~m}^{3} / \mathrm{s}\right)$ \\
\hline & $V_{p}$ & $3.53\left(\mathrm{~m}^{3}\right)$ \\
\hline & $K_{p}$ & $0.16 \mathrm{E}-3\left(\mathrm{~m}^{2}\right)$ \\
\hline \multirow[t]{3}{*}{ Mixing box } & $Q_{m b}$ & $0.500\left(\mathrm{~m}^{3} / \mathrm{s}\right)$ \\
\hline & $Q_{m b, \text { med }}$ & $0.495\left(\mathrm{~m}^{3} / \mathrm{s}\right)$ \\
\hline & $V_{m b}$ & $0.16\left(\mathrm{~m}^{3}\right)$ \\
\hline \multirow[t]{22}{*}{ DMC } & $Q_{c, i}$ & $0.500\left(\mathrm{~m}^{3} / \mathrm{s}\right)$ \\
\hline & $V_{c}$ & $0.38\left(\mathrm{~m}^{3}\right)$ \\
\hline & $\alpha$ & 2 \\
\hline & $\rho_{c, a s h}$ & $2000\left(\mathrm{~kg} / \mathrm{m}^{3}\right)$ \\
\hline & $\rho_{c, S}$ & $1920\left(\mathrm{~kg} / \mathrm{m}^{3}\right)$ \\
\hline & $\rho_{c, v o l}$ & $1100\left(\mathrm{~kg} / \mathrm{m}^{3}\right)$ \\
\hline & $\rho_{c, \mathrm{H}_{2} \mathrm{O}}$ & $1000\left(\mathrm{~kg} / \mathrm{m}^{3}\right)$ \\
\hline & $\rho_{c, i, \text { med }}-\rho_{c, o, \text { med }}$ & $100\left(\mathrm{~kg} / \mathrm{m}^{3}\right)$ \\
\hline & $\rho_{c, u, \text { med }}-\rho_{c, i, \text { med }}$ & $100\left(\mathrm{~kg} / \mathrm{m}^{3}\right)$ \\
\hline & $Q_{c, i, m e d}$ & $0.495\left(\mathrm{~m}^{3} / \mathrm{s}\right)$ \\
\hline & $K_{c, o}$ & $0.22\left(\mathrm{~m}^{2} \mathrm{~s}\right)$ \\
\hline & $K_{c, u}$ & $0.22\left(\mathrm{~m}^{2} \mathrm{~s}\right)$ \\
\hline & $K_{c, o, a s h}$ & $200 \mathrm{E}-6\left(\mathrm{~m}^{3} \mathrm{~s} / \mathrm{kg}\right)$ \\
\hline & $K_{c, u, a s h}$ & $77 \mathrm{E}-6\left(\mathrm{~m}^{3} \mathrm{~s} / \mathrm{kg}\right)$ \\
\hline & $K_{c, o, S}$ & $390 \mathrm{E}-6\left(\mathrm{~m}^{3} \mathrm{~s} / \mathrm{kg}\right)$ \\
\hline & $K_{c, u, S}$ & $390 \mathrm{E}-6\left(\mathrm{~m}^{3} \mathrm{~s} / \mathrm{kg}\right)$ \\
\hline & $K_{c, o, H_{2} \mathrm{O}}$ & $150 \mathrm{E}-6\left(\mathrm{~m}^{3} \mathrm{~s} / \mathrm{kg}\right)$ \\
\hline & $K_{c, u, H_{2} \mathrm{O}}$ & $30 \mathrm{E}-6\left(\mathrm{~m}^{3} \mathrm{~s} / \mathrm{kg}\right)$ \\
\hline & $K_{c, o, v o l}$ & $890 \mathrm{E}-6\left(\mathrm{~m}^{3} \mathrm{~s} / \mathrm{kg}\right)$ \\
\hline & $K_{c, u, v o l}$ & $8.9 \mathrm{E}-6\left(\mathrm{~m}^{3} \mathrm{~s} / \mathrm{kg}\right)$ \\
\hline & $K_{c, o, \text { med }}$ & $480 \mathrm{E}-6\left(\mathrm{~m}^{3} \mathrm{~s} / \mathrm{kg}\right)$ \\
\hline & $K_{c, u, \text { med }}$ & $390 \mathrm{E}-6\left(\mathrm{~m}^{3} \mathrm{~s} / \mathrm{kg}\right)$ \\
\hline \multirow{4}{*}{$\begin{array}{l}\text { Magnetite make-up } \\
\text { corrected medium tank }\end{array}$} & $Q_{t, \text { med }}$ & $0.495\left(\mathrm{~m}^{3} / \mathrm{s}\right)$ \\
\hline & $Q_{t}$ & $0.495\left(\mathrm{~m}^{3} / \mathrm{s}\right)$ \\
\hline & $A_{t}$ & $0.28\left(\mathrm{~m}^{2}\right)$ \\
\hline & $h_{t, \max }$ & $1.5(\mathrm{~m})$ \\
\hline
\end{tabular}

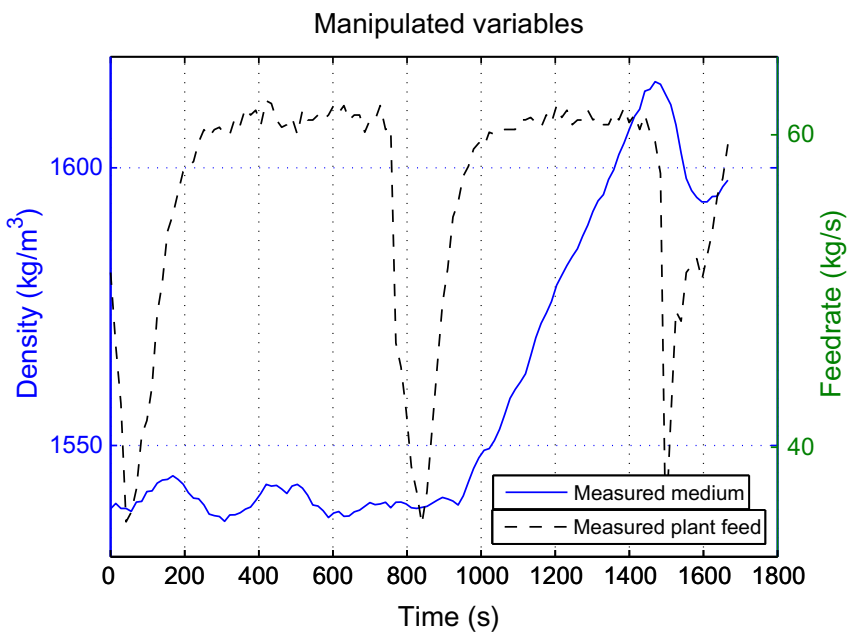

Fig. 20. Industrial step test for fine cyclone circuit. 
Table 11

Laboratory results for fine cyclone circuit step test.

\begin{tabular}{|c|c|c|c|c|c|}
\hline & Time & $\%$ Ash & \% Moisture & $\%$ Volatiles & $\%$ Fixed carbon \\
\hline \multirow[t]{6}{*}{ Fine cyclone product screen } & $12: 15$ & 14.5 & 0.9 & 11.8 & 72.8 \\
\hline & $12: 20$ & 14.5 & 1.3 & 12.3 & 71.9 \\
\hline & $12: 25$ & 15.6 & 1.5 & 11.1 & 71.8 \\
\hline & $12: 30$ & 16.0 & 1.4 & 11.9 & 70.7 \\
\hline & $12: 35$ & 15.8 & 1.5 & 12.3 & 70.4 \\
\hline & $12: 40$ & 16.1 & 1.5 & 12.9 & 69.5 \\
\hline Average & & 15.4 & 1.4 & 12.1 & 71.2 \\
\hline Standard deviation & & 0.73 & 0.23 & 0.61 & 1.20 \\
\hline
\end{tabular}

The manipulated variable in the DMS plant is the medium density for each DMC. Since it was difficult to take samples of the feed ore and product from the coarse and ultrafine cyclones, only the fine cyclone circuit was used. Fig. 20 illustrates the change in density setpoint that was made for the step test on the fine cyclone circuit and the measured ore feed rate conveyed into the plant. During the step test, the feed rate of the ore into the plant dropped owing to the control system that is currently implemented. The reason for this is to ensure that no spillages occur at the product conveyor belts.

During the step test representative samples were collected by a South African Bureau of Standards-approved laboratory every 5 min from the product washing screen of the fine cyclone. The laboratory results from the samples can be found in Table 11 .

\subsection{Model input}

As input to the model, the manipulated variables of the process include the feed rate of ore into the plant and the density setpoint of the medium. These variables are measured and time trends are shown in Fig. 20. The data used for input to the model has a sample period of $14 \mathrm{~s}$.

\section{Simulation results and discussion}

By interconnecting and simulating the models described in Section 3, using the input from Section 4.4 and incorporating the parameters from Section 4.2, it is possible to simulate each equipment model. The Runge-Kutta approximation (Mathews and Fink, 1999) can be used to solve the differential equations describing the models.

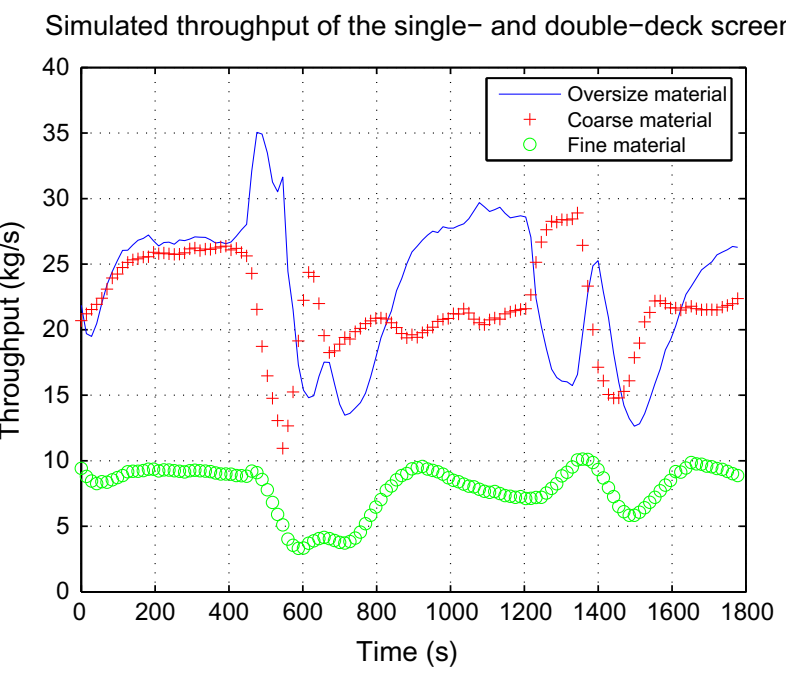

Fig. 21. Simulated throughput for single and double-deck screens.
Measurements of the product qualities during the industrial experiment (Table 11) are also required to allow the comparison of actual product components to the simulation, specifically for the DMC.

\subsection{Single- and double-deck screens}

Fig. 21 illustrates the simulated response for the double-deck and single-deck screen products. In this simulation it was estimated that the feed ore measurement takes approximately $140 \mathrm{~s}$ before it actually reaches the double-deck screen. This transfer delay approximation was accepted by the plant metallurgist as a reasonable estimate (Lundt, 2008). The correlation between the simulated oversize material and actual oversize measurement is 0.89 . The average yield for the double-deck screen oversized material is $41 \%$. For the coarse material, the average yield is $39 \%$. The undersized material from the bottom deck is collected and used as input for the single-deck screen simulation. The yield for this fine material is $71 \%$.

The correlation between the simulated oversize material and actual oversize measurement is high. This high correlation means that the model predicts the oversize material accurately. The yield for the different sized products is also comparable to that of what the mine from which the experimental test was conducted typically obtains.

\subsection{Magnetite medium water addition}

Fig. 22 illustrates the simulated response of the water-addition model for the medium RD control. This model input is the medium-density response from the DMC simulation. The other model input is the valve position for the addition of water. It is assumed

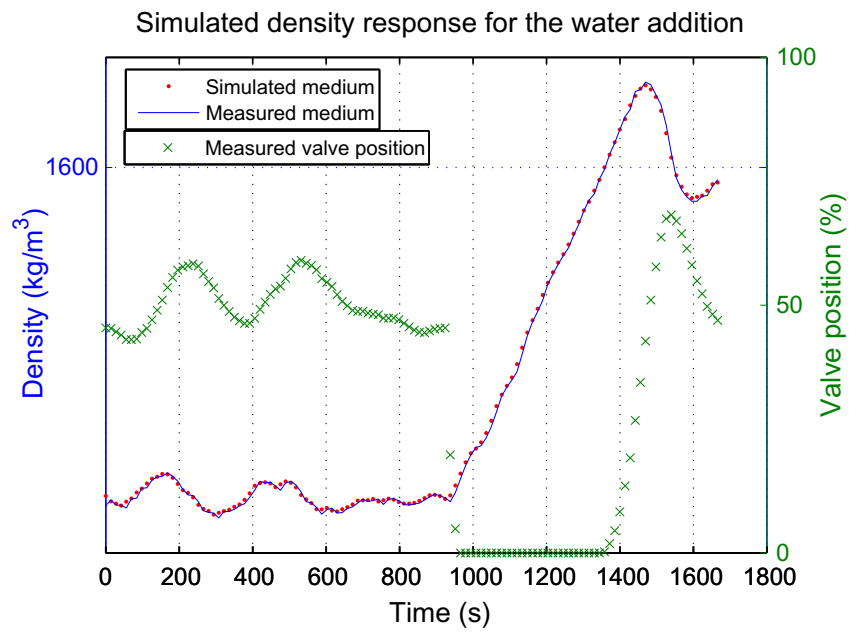

Fig. 22. Simulated response of the water-addition model. 


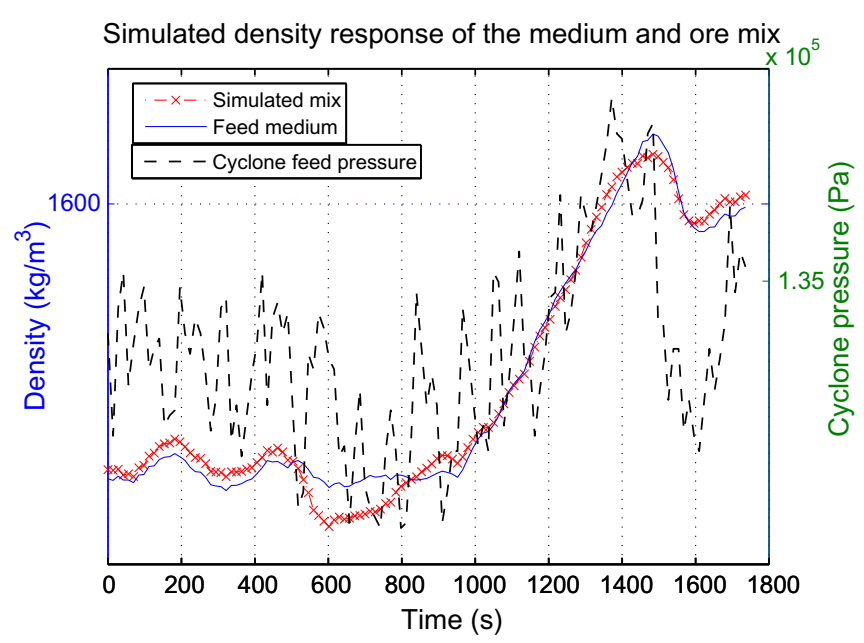

Fig. 23. Simulated response of the mixing box output.

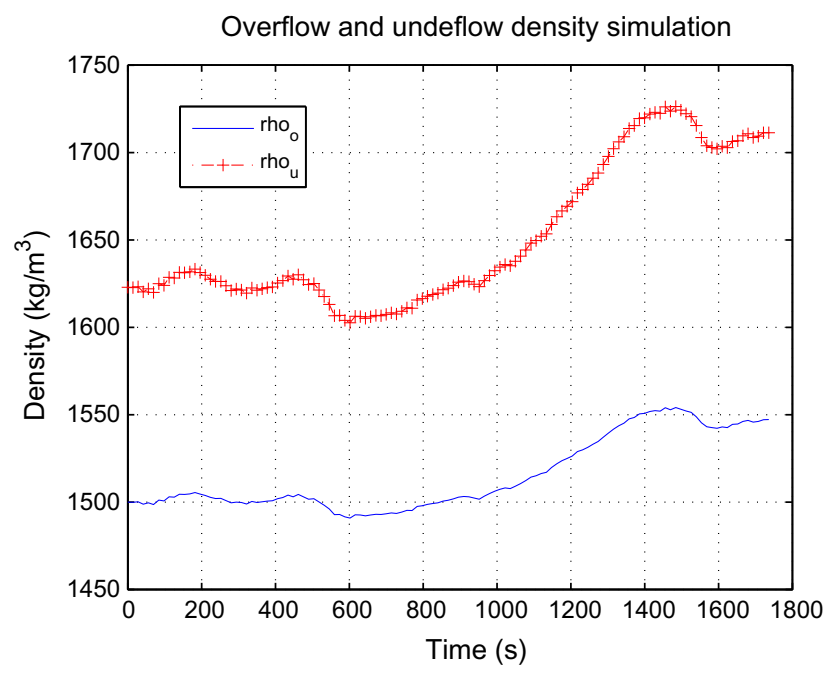

Fig. 24. Simulated overflow and underflow densities.

that the DMC medium density is delayed by $14 \mathrm{~s}$ before it reaches the water-addition model. This transfer delay approximation was accepted by the plant metallurgist as a reasonable estimate (Lundt, 2008). It is also assumed that there are no losses of medium in the recovery stage.

The correlation between the simulated response and actual density measurement is 1.00 . The high correlation in the wateraddition comparison means that the model predicts the output accurately.

\subsection{Mixing box}

Fig. 23 illustrates the simulated response of the mixing box density output. The simulated fines output from the single-deck screen is used as input for the ore feed into the mixing box. The actual medium-density measurement is used as the second input to this model. It is assumed that the medium takes $28 \mathrm{~s}$ from its measurement point to reach the mixing box. This transfer delay approximation was accepted by the plant metallurgist as a reasonable estimate (Lundt, 2008). The cyclone feed pressure can be used as an indication of how the mix density responds and can be compared to the simulated output. The oscillations in the pressure could be a result of the pump cavitating or the vibrations of the screens.

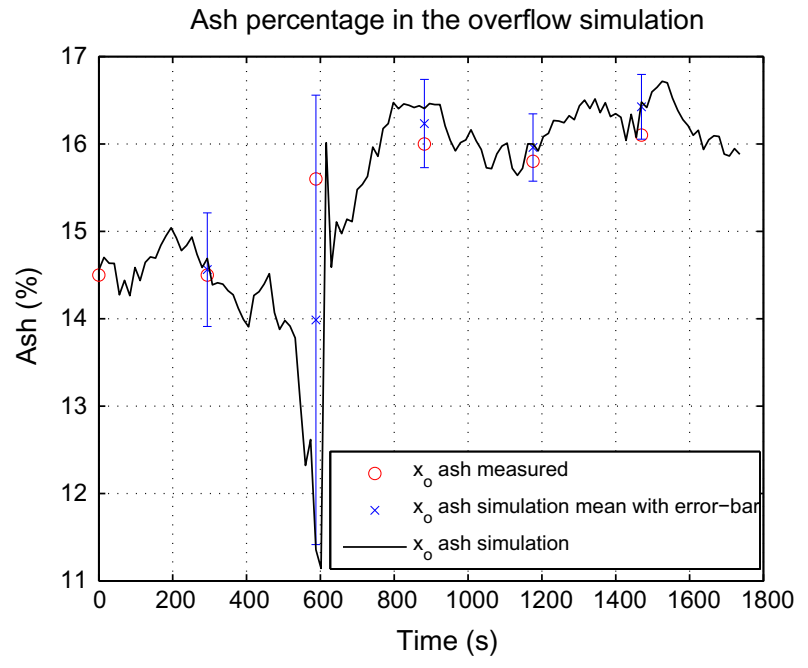

Fig. 25. Comparison of simulated, simulated mean with error-bar (95\% confidence interval) and measured ash percentage in overflow.

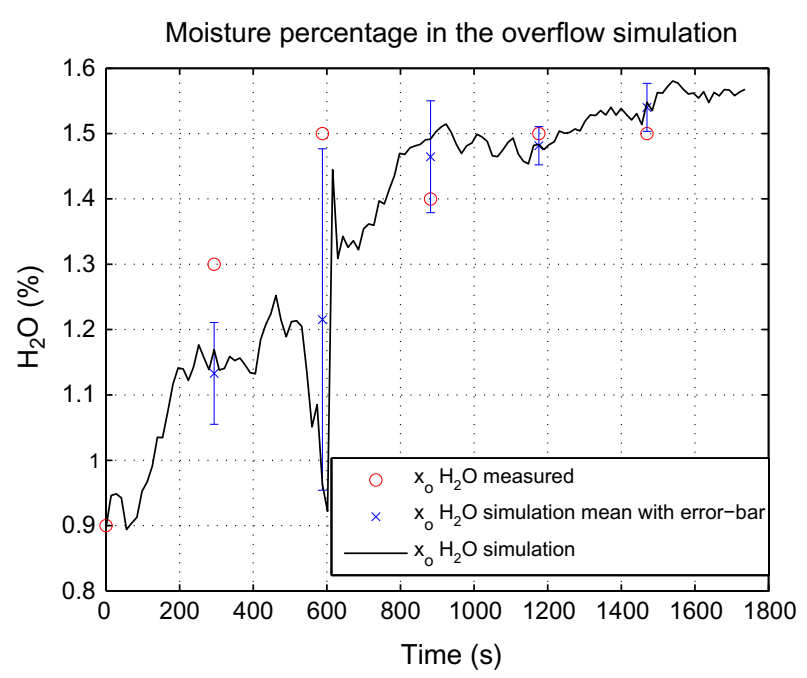

Fig. 26. Comparison of simulated, simulated mean with error-bar ( $95 \%$ confidence interval) and measured moisture percentage in overflow.

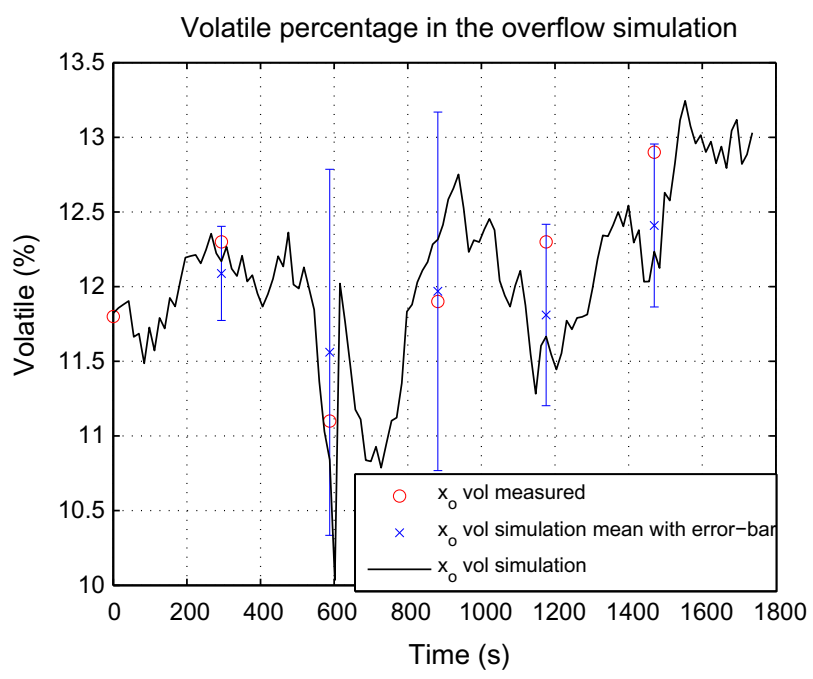

Fig. 27. Comparison of simulated, simulated mean with error-bar (95\% confidence interval) and measured volatile percentage in overflow. 
Simulated density response for the magnetite medium makeup tank

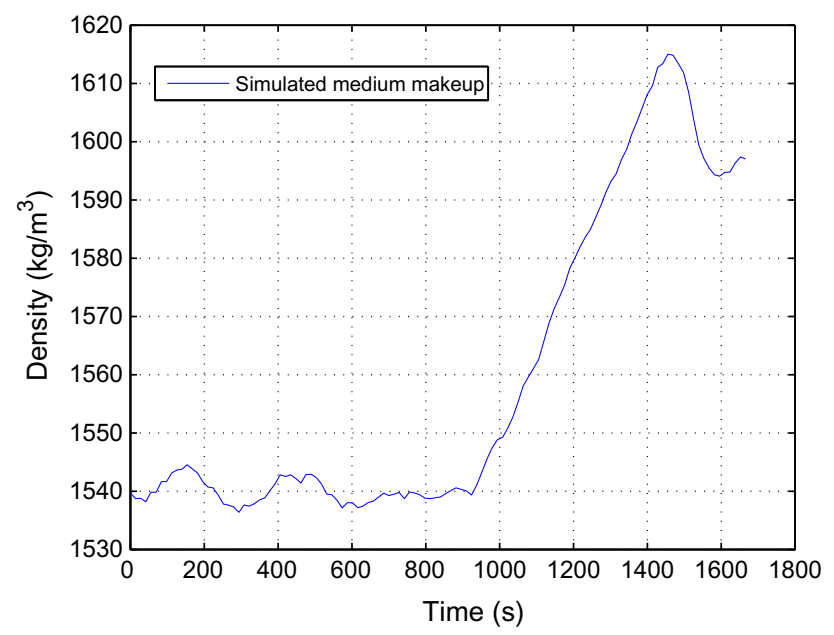

Fig. 28. Simulated response of the medium make-up.

Table 12

Simulation comparison results summary.

\begin{tabular}{ll}
\hline Equipment model & Correlation \\
\hline Magnetite medium water addition & 1.00 \\
DMC & \\
Ash & 0.72 \\
Moisture & 0.80 \\
Volatile & 0.72 \\
\hline
\end{tabular}

\section{4. $D M C$}

Fig. 24 illustrates the simulated DMC overflow and underflow density responses. The underflow density response is larger than the overflow density response. Fig. 25 illustrates a comparison between the simulated and actual ash percentage response. Since samples could only be taken every 5 min for analysis, the simulated mean for every $5 \mathrm{~min}$ was also computed. The laboratory results can be found in Table 11 .

The correlation for the ash comparison is 0.72. Similarly the moisture and volatile components are simulated and illustrated in Figs. 26 and 27. The moisture comparison has a correlation of 0.80 . For the volatile comparison the correlation is 0.72 .

If the samples for the DMC model were taken at faster intervals, the deviations shown in the error-bars for Figs. 25-27 will be reduced. Due to the limitation in sampling the product every 5 min (Table 11) during the industrial experiment, the number of samples obtained is small. Since most of the measured product ash, moisture and volatile percentages lie within the $95 \%$ confidence interval for the error-bars in Figs. 25-27, the model predicts the different outputs with a reasonable degree of accuracy.

\subsection{Magnetite make-up corrected medium tank}

Fig. 28 illustrates the simulated response for the magnetite make-up corrected medium tank. The medium-density response from the DMC is used as input for this model. The tank height is incorporated into this model by making use of the Runge-Kutta approximation.

\subsection{Results summary}

The correlation for each simulation comparison (where applicable) is summarised in Table 12 .

\section{Conclusion}

This work illustrates how dynamic models of a coal beneficiation DMS circuit can be developed from first principles. The models were developed from first principles as no such models could be found in the current published literature. Each equipment model in the DMS circuit was developed using the conservation of overall mass. The conservation of mass of components was used to model the ash, moisture and volatile percentages for the DMC.

The equipment models were found to be non-linear, and the model parameters were identified and estimated to a reasonable degree of accuracy. The validation of the models was performed using an industrial experiment test case where plant data were collected and samples were taken from a fine cyclone product and analysed. During the test case, the medium density for fine cyclone circuit was adjusted by introducing a step change. The high correlation of $100 \%$ for the magnetite medium water addition, $72 \%$ for the ash and volatile in the DMC overflow, and $80 \%$ for the moisture in the DMC overflow indicate that the models simulate the DMS process reasonably well.

By analysing the performance of an existing DMS plant, it was found that improvements could be made with better process control. The models developed in this work can be used for the design of a DMS plant controller in future.

\section{Acknowledgements}

Our appreciation goes to Exxaro Resources for their support and approval for conducting an industrial experiment at one of their coal preparation sites to enable us to validate the models that have been developed. Acknowledgement also goes to the National Research Foundation of South Africa for providing additional funding for this research.

\section{References}

Bauer, M., Craig, I.K., 2008. Economic assessment of advanced process control - a survey and framework. Journal of Process Control 18, 2-18.

Brennan, M.S., 2003. Multiphase CFD simulations of dense medium and classifying hydrocyclones. In: Proceedings of the Third international Conference on CFD in the Minerals and Process Industries CSIRO, 10-12 December, 2003, Melbourne, Australia, pp. 59-64.

Chen, W., Zydek, N., Parma, F., 2000. Evaluation of hydrocyclone models for practical applications. Chemical Engineering Journal 80, 295-303.

Clarkson, C.J., 1983. A model of dense medium cyclones. In: Proceedings of the Dense Medium Operators Conference, 1983, Brisbane, Australia, pp. 235-245.

Cortés, C., Gil, A., 2007. Modelling the gas and particle flow inside cyclone separators. Progress in Energy and Combustion Science 33, 409-452.

Craig, I.K., Henning, R.G.D., 2000. Evaluation of advanced industrial control projects: a framework for determining economic benefits. Control Engineering Practice 8, 769-780.

de Korte, J.G., 2003a. Comments on the use of tracers to test dense-medium plant efficiency. International Journal of Coal Preparation and Utilization 23 (5), 251 266.

de Korte, J.G., 2003b. Index of South African Coal Preparation Plants. <http:// www.sacoalprep.co.za/information.html> (accessed 30.10.08).

England, T., Hand, P.E., Michael, D.C., Falcon, L.M., Yell, A.D., 2002. Coal Preparation in South Africa, fourth ed. Natal Witness Commercial Printers, Pietermaritzburg South Africa.

Erasmus, T.C., 1973. The Fitting of a Smooth Curve to the Experimentally Determined Coordinates of a Tromp Curve. Tech. Rep. 4, Fuel Research Institute of South Africa.

Firth, B.A., Grice, C., Jenssen, E., Weale, W., 1983. Computer simulation of coal preparation and its application at the Saxonvale mine. In: Proceedings of the Second Australian Coal Preparation Conference, 10-14 October, 1983, Rockhampton, Australia, vol. 2. Australian Coal Preparation Society, pp. 421443.

Gottfried, B.S., 1973. Computer Simulation of Coal Preparation Plants. Tech. Rep. Grant No. G0-155030, US Bureau of Mines.

Honaker, R.Q., Patwardhan, A., 2006. In-plant evaluation of dense medium process performances. International Journal of Coal Preparation and Utilization 26 (3), 149-164.

King, R.P., Juckes, A.H., 1984. Cleaning of fine coals by dense-medium hydrocyclones. Powder Technology 40 (1), 147-160. 
King, R.P., Juckes, A.H., 1988. Performance of dense-medium cyclone when beneficiating fine coal. Coal Preparation 5, 185-210.

Lipták, B.G., 1995. Instrument Engineers' Handbook: Process Control, third ed Butterworth-Heinemann Ltd., UK, Europe.

Ljung, L., 1987. System Identification: Theory for the User, first ed. Prentice-Hall, Inc., Englewood Cliffs, NJ.

Lundt, M., 2008. Leeuwpan DMS Plant Delay Estimates, private communication.

Lynch, A.J., 1977. Mineral Crushing and Grinding Circuits - Their Simulation, Optimisation, Design and Control. Elsevier Scientific Pub. Co., Amsterdam.

Majumder, A.K., Barnwal, J.P., Ramakrishnan, N., 2004. A new approach to evaluate the performance of gravity-based coal washing equipment International Journal of Coal Preparation and Utilization 24 (5), 277284.

Mathews, J.H., Fink, K.D., 1999. Numerical Methods Using Matlab. third ed. PrenticeHall Inc., USA.

Napier-Munn, T.J., 1991. Modelling and simulating dense medium separation processes - a progress report. Minerals Engineering 4 (3), 329-346.

Plitt, L.R., 1971. The analysis of solid-solid separations in classifiers. In: The Can Minerals Metalurgy, Bul. pp. 1-6.
Rao, B.V., 2004. Weibull partition surface representation for gravity concentrators. Minerals Engineering 17, 953-956.

Rao, B.V., Kapur, P.C., Konnur, R., 2003. Modelling the size-density partition surface of dense-medium separators. International Journal of Mineral Processing 72 443-453.

Rathaba, L.P., 2004. Model Fitting for Electric Arc Furnace Refining. Master's thesis, University of Pretoria.

Scott, I.A., Lyman, G.J., 1987. Metallurgical evaluation of iron ore drum separators using density tracers. In: Proceeding of the Australian Institute of Mining and Metallurgy, February, 1987, vol. 1, pp. 49-56.

Scott, I.A., Napier-Munn, T.J., 1992. Dense-medium cyclone model based on the pivot phenomenon. Transactions of the Institution of Mining and Metallurgy (Section C: Min. Proc. Extr. Metall.) 101, C61-C76.

Suasnabar, D.J., Fletcher, A.J., 1999. A CFD model for dense medium cyclones. In: Proceedings of the Second international Conference on CFD in the Minerals and Process Industries CSIRO, 6-8 December, 1999, Melbourne, Australia, pp. 199204

Xia, X., Moog, C.H., 2003. Identifiability of nonlinear systems with applications to HIV/AIDS models. IEEE Transactions on Automatic Control 48 (2), 330-336. 